\title{
Tissue-specific differentiation of colonic macrophages requires TGF $\beta$ receptor-mediated signaling
}

\author{
A Schridde ${ }^{1,2,3,6}$, CC Bain ${ }^{1,6,7}$, JU Mayer ${ }^{1}$, J Montgomery ${ }^{1}$, E Pollet ${ }^{4}$, B Denecke ${ }^{5}$, SWF Milling ${ }^{1}$,

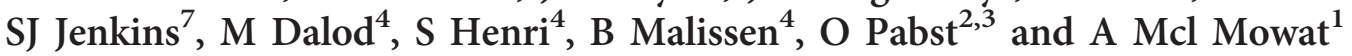

Intestinal macrophages $(m \phi)$ form one of the largest populations of $m \phi$ in the body and are vital for the maintenance of gut homeostasis. They have several unique properties and are derived from local differentiation of classical Ly6 $\mathrm{C}^{\text {hi }}$ monocytes, but the factors driving this tissue-specific process are not understood. Here we have used global transcriptomic analysis to identify a unique homeostatic signature of mature colonic $\mathrm{m} \phi$ that is acquired as they differentiate in the mucosa. By comparing the analogous monocyte differentiation process found in the dermis, we identify TGF $\beta$ as an indispensable part of monocyte differentiation in the intestine and show that it enables $\mathrm{m} \phi$ to adapt precisely to the requirements of their environment. Importantly, TGF $\beta R$ signaling on $m \phi$ has a crucial role in regulating the accumulation of monocytes in the mucosa, via mechanisms that are distinct from those used by IL10.

\section{INTRODUCTION}

Macrophages $(\mathrm{m} \phi)$ are present in most tissues of the body, where they scavenge dying cells, remodel tissues and act as sources of growth factors for neighboring parenchymal cells and leukocytes. ${ }^{1}$ During infection or inflammation, they ingest and kill invading microbes and produce pro-inflammatory mediators. $^{2}$ Despite many similarities, there is increasing evidence that $\mathrm{m} \phi$ in distinct steady state tissues differ in terms of ontogeny, phenotype, and functions. ${ }^{3}$

The discovery that the yolk sac mesenchyme, fetal monocytes, and adult bone marrow (BM) derived monocytes could all generate resident $\mathrm{m} \phi$ led to the idea that tissue-specific differences among mature $m \phi$ might reflect their origin from distinct precursors. Thus, although microglia are derived almost entirely from self-renewal of yolk sac precursors, ${ }^{4-6}$ alveolar $\mathrm{m} \phi$, liver Kupffer cells, and epidermal Langerhans cells are derived from fetal liver monocytes. ${ }^{5-7}$ Conversely, we have shown that intestinal $\mathrm{m} \phi$ require constant replenishment by BM-derived monocytes throughout adult life. ${ }^{8,9}$ Adult monocyte-derived $\mathrm{m} \phi$ are also present to different degrees in other tissues such as dermis, ${ }^{10}$ heart, ${ }^{11-13}$ and the serous cavities. ${ }^{14}$ However, more recent work makes it clear that developmental origin alone does not explain the heterogeneity seen among $m \phi$ from different anatomical sites, as these have unique molecular signatures even when derived from the same progenitor. ${ }^{15}$ Furthermore, transcriptionally identical $\mathrm{m} \phi$ develop upon adoptive transfer into the neonatal lung, irrespective of the type of precursor used. ${ }^{16}$ Thus, tissuederived signals appear to be the principal determinant of resident $\mathrm{m} \phi$ fate.

The intestinal mucosa contains one of the largest populations of $\mathrm{m} \phi$ in the body. ${ }^{17}$ Although initially embryo-derived, intestinal $\mathrm{m} \phi$ are derived entirely from circulating Ly $6 \mathrm{C}^{\text {hi }}$ monocytes from the time of weaning onwards. ${ }^{9}$ Under steady state conditions, these monocytes differentiate through a series of short-lived intermediaries to generate mature $\mathrm{m} \phi$ characterized by expression of high levels of CD11b, MHCII, CX3CR1, and $\mathrm{CD} 11 \mathrm{c}$, production of IL10 and relative desensitization to

${ }^{1}$ Centre for Immunobiology, Institute of Infection, Immunity and Inflammation, College of Medicine, Veterinary Medicine and Life Sciences, University of Glasgow, Scotland, UK. ${ }^{2}$ Institute of Immunology, Hannover Medical School, Hannover, Germany. ${ }^{3}$ Institute of Molecular Medicine, RWTH Aachen, Aachen, Germany. ${ }^{4}$ Centre d'Immunologie de Marseille-Luminy, Aix Marseille Université, INSERM, CNRS, Marseille, France and ${ }^{5}$ Genomics Facility IZKF, RWTH Aachen, Aachen, Germany. Correspondence: A Mcl Mowat (Allan.Mowat@glasgow.ac.uk)

${ }^{6}$ These authors contributed equally to this work.

${ }^{7}$ Current address: MRC Centre for Inflammation Research, University of Edinburgh, UK. 
conventional stimuli. ${ }^{8,18,19}$ However, during inflammation this differentiation process is disrupted resulting in the accumulation of immature, pro-inflammatory cells. ${ }^{8,18,20,21}$ Thus, the fate of Ly6 $\mathrm{C}^{\text {hi }}$ monocytes in the intestine is dependent on the context of the environment into which they arrive.

Although recent studies have identified retinoic acid and CSF2/PPAR $\gamma$ ligands as local environmental signals that imprint the unique signature of peritoneal and alveolar $\mathrm{m} \phi$, respectively, ${ }^{7,22,23}$ the equivalent factors in the intestine have not been elucidated. Here we use global transcriptomic analysis to identify a unique genetic signature of steady state colonic $\mathrm{m} \phi$ that is acquired as they differentiate locally from Ly6 $\mathrm{C}^{\text {hi }}$ monocytes via a process known as the 'monocyte waterfall', 8,18 Through comparison with the analogous process found in the dermis, we identify TGF $\beta R$ signaling as an indispensable part of monocyte differentiation in the gut and show that it allows intestinal $\mathrm{m} \phi$ to adapt precisely to the special requirements of their environment. By combining conditional TGF $\beta R 1$-deficient mice with BM chimera models, we demonstrate that TGF $\beta R$ signaling on $m \phi$ limits monocyte recruitment to the mucosa, via mechanisms that appear distinct from those used by IL10.

\section{RESULTS}

\section{Transcriptomic analysis of colonic $\mathrm{m} \phi$ differentiation}

To explore the processes that govern $m \phi$ differentiation in the intestine, we first performed whole transcriptome array analysis of FACS purified mature $\mathrm{CD}^{+} 4^{+}$ CX3CR $1{ }^{\text {hi }} \mathrm{Ly}_{6 \mathrm{C}^{-}} \mathrm{MHCII}^{+}$colonic m $\phi$ and compared the results with published data sets for peritoneal, lung, brain, spleen, and BM m $\phi$ (Immgen Consortium), as well as with the mature dermal $\mathrm{m} \phi .{ }^{10}$ Consistent with the idea that resident $\mathrm{m} \phi$ show tissue specific specialization, the different populations clustered separately both when comparing entire transcriptomes (Figure 1a) or the 37 genes suggested to describe a $\mathrm{m} \phi$ 'core signature ${ }^{\text {,24 }}$ (Supplementary Figure 1a online). Both approaches showed that colonic $\mathrm{m} \phi$ were more closely related to those from the dermis than to other tissue $m \phi$ (Figure 1a and Supplementary Figure 1a). Further analysis revealed that 108 genes were differentially expressed by at least twofold in colonic $\mathrm{m} \phi$ compared with all other tissue $\mathrm{m} \phi$ assessed and these can be considered as comprising a putative signature for colonic $\mathrm{m} \phi$. They included $C d 4$ and the inhibitory receptor Illr2, as well as genes that encode the tight junction proteins Amical, Cdh17, and Cldn7, members of the Notch pathway (Hes1, $D t x 3), C x c l 9$, Tlr 12 , and the TGF $\beta$ superfamily receptor $T d g f 1$ (Supplementary Figure 1b).

To gain further insight into how local factors shape the selective characteristics of $m \phi$ in the intestine, we analyzed the differentiation stages within the "monocyte waterfall" that generates intestinal $\mathrm{m} \phi$ from their monocyte precursors. ${ }^{8,9,18}$ In this scheme, newly arrived monocytes are $\mathrm{Ly}_{6} \mathrm{C}^{\text {hi }} \mathrm{MHCII}^{-}$ CX3CR $1^{\text {int }}(\mathrm{P} 1)$, two intermediate subsets can be identified as $\mathrm{Ly}_{6} \mathrm{C}^{\mathrm{hi}} \mathrm{MHCII}{ }^{+} \mathrm{CX} 3 \mathrm{CR} 1^{\text {int }}$ (P2) and $\mathrm{Ly}^{-} \mathrm{C}^{-} \mathrm{MHCII}^{+}$ $\mathrm{CX}^{\mathrm{CCR}} 1^{\text {int }}(\mathrm{P} 3)$; mature $\mathrm{m} \phi$ are $\mathrm{Ly}^{-} \mathrm{C}^{-} \mathrm{MHCII}^{+} \mathrm{CX} 3 \mathrm{CR} 1^{\text {hi }}$ $(\mathrm{P} 4)^{8,18}$ (Figure 1b). Analysis of the transcriptomes of these phenotypic subsets in the colon revealed a clear progression in gene expression, consistent with them being components of a linear maturation continuum (Figure 1c). In total, 1,004 genes changed by more than twofold between newly arrived Ly6 $\mathrm{C}^{\text {hi }}$ monocytes (P1) and CX3CR1 ${ }^{\text {hi }}$ mature (P4) $\mathrm{m} \phi$ (Supplementary Table 1). Among the 391 genes that were downregulated were molecules involved in the chemotaxis and extravasation of monocytes, such as $\mathrm{Ccr} 2$, Sell (which encodes CD62L), Ly6c1, Gpr35 (CXCR8), Itga1 (VLA-1), Itgal (LFA-1), and $\operatorname{Itgb7}(\beta 7$ integrin) (Figure 1d). Flow cytometry confirmed the decreasing expression of CCR2 and $\beta 7$ integrin proteins during the maturation process in the colon and small intestine (Figure 1e and Supplementary Figure 2). Other highly downregulated genes included the pro-inflammatory factors Il6 and Trem 1 (triggering receptor expressed on myeloid cells) and adaptor proteins within the TLR activation pathway (Myd88, Irak3) (Figure 1d).

Six hundred and thirteen genes were upregulated in mature P4 m $\phi$ compared with newly arrived P1 monocytes (Supplementary Table 1). Many of these were consistent with mature colonic $m \phi$ having an important role in tissue homeostasis, as they included genes encoding receptors involved in the phagocytosis and uptake of apoptotic cells (Mertk, Mrc1 (CD206), Cd36, Gas6, Axl, Itgav, Itgb5, Cd9, Cd81, C1qa-c), tissue remodeling metalloproteinases (Mmp2

Figure 1 Transcriptomic analysis of the monocyte-macrophage differentiation series in normal colonic mucosa. (a) Hierarchical cluster analysis of mature colonic macrophages $\left(\mathrm{CD} 11 \mathrm{~b}^{+} \mathrm{CD} 64^{+} \mathrm{Ly}_{6 \mathrm{C}^{-}} \mathrm{MHClI}^{+} \mathrm{CX} 3 \mathrm{CR} 1^{\mathrm{hi}}\right)$ compared with macrophages from the lung, brain, bone marrow, spleen, peritoneal cavity, and dermis (ANOVA; $P_{\text {Raw }} \leq 0.05 ; P_{\text {Adj }} \leq 0.037$ ). (b) Expression of Ly6C and MHCll by CD $45^{+}$CD11b ${ }^{+}$CD $64^{+}$cells (upper panel)

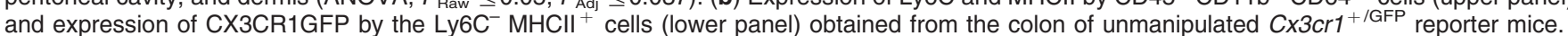
Data are representative of at least 20 independent experiments. (c) Global gene expression profile of $\mathrm{Ly}^{6} \mathrm{C}^{+} \mathrm{MHCII}^{-}(\mathrm{P} 1), \mathrm{Ly}^{2} \mathrm{C}^{+} \mathrm{MHCll}^{+}(\mathrm{P} 2)$,

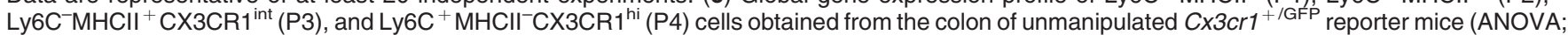
$P_{\text {Raw }} \leq 0.05 ; P_{\text {Adj }} \leq 0.08$ ). (d) Functionally defined subsets of mRNA transcripts that are significantly downregulated during differentiation from the P1 to $\mathrm{P} 4$ stage in the colon of unmanipulated $C \times 3 \mathrm{cr} 1^{+/ \mathrm{GFP}}$ reporter mice. (Student's $t$-test; $P \leq 0.05$; fold change $\geq 2.0$ ). (e) Flow cytometric analysis of CCR2 and integrin $\beta 7$ expression by P1-P4 subsets obtained from the colon and small intestine of unmanipulated $C \times 3 \mathrm{cr} 1^{+/ G F P}$ reporter mice compared with the appropriate isotype control. Data are representative of 3-4 independent experiments. (f) Functionally defined subsets of mRNA transcripts that are significantly upregulated during differentiation from the P1 to P4 stage in the colon of unmanipulated $C \times 3 c r 1^{+/ G F P}$ reporter mice. (Student's $t$-test; $P \leq 0.05$; fold change $\geq 2.0$ ). (g) Subset-specific expression of genes that are progressively upregulated from the P1 to P4 stages and expressed at least twofold higher by mature colonic macrophages compared with any of the tissue resident macrophage populations as in a above. (Student's $t$-test $P \leq 0.05$, fold change $\geq 2.0$ ). (h) Flow cytometric analysis of the expression of cell surface markers identified in $\mathrm{f}$ above by P1-P4 subsets obtained from the colon and small intestine of unmanipulated $C \times 3 \mathrm{cr}^{+/ G F P}$ reporter mice compared with appropriate isotype controls. Data are representative of 3-4 independent experiments. 
and $\mathrm{Mmp9}$ ), monocyte chemoattractants ( $\mathrm{Ccl} 7$ and $\mathrm{Ccl} 8$ ) and components of the complement cascade (Figure 1f). Other highly upregulated genes were members of the TGF $\beta R$ signaling pathway $(T g f b r 1 / 2, S m a d 7)$ and genes encoding molecules already known to be highly expressed by colonic m $\phi$, including Cx3cr1, MHCII associated H2-M2, Itgax (CD11c), Emr1 (F4/80), and Il10 (Figure 1f). Forty-two of these upregulated genes were amongst the 108 genes identified a

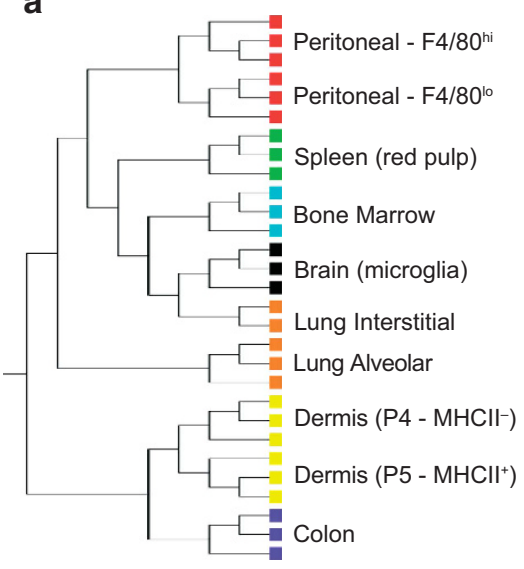

b



d

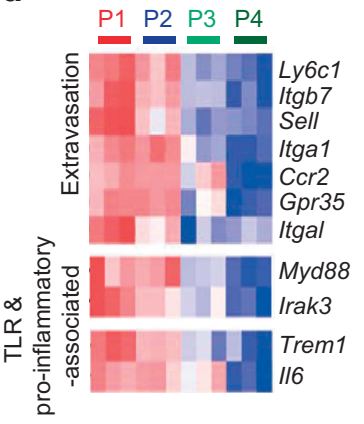

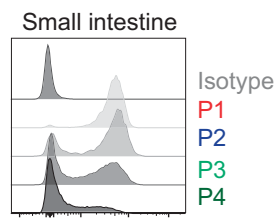
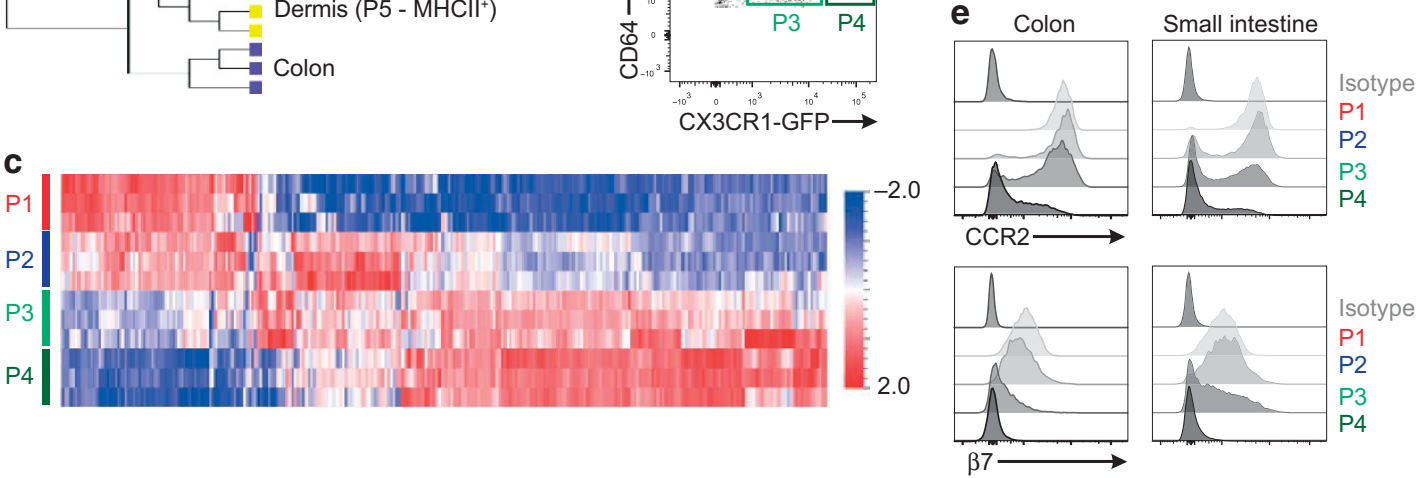

f

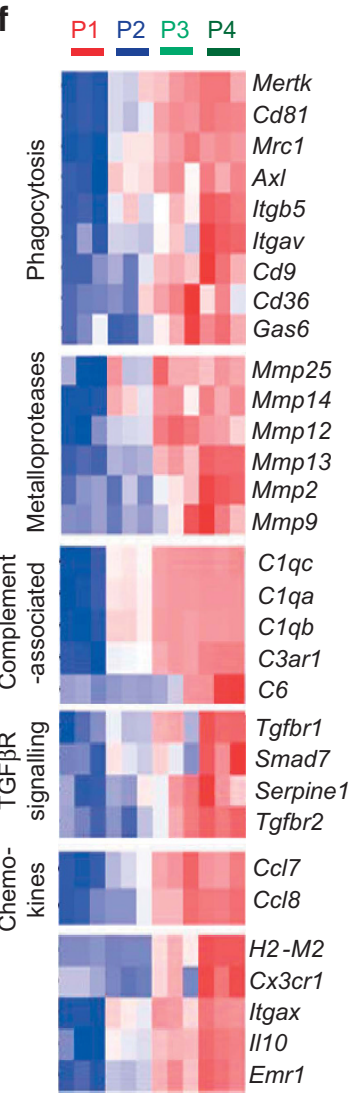

g

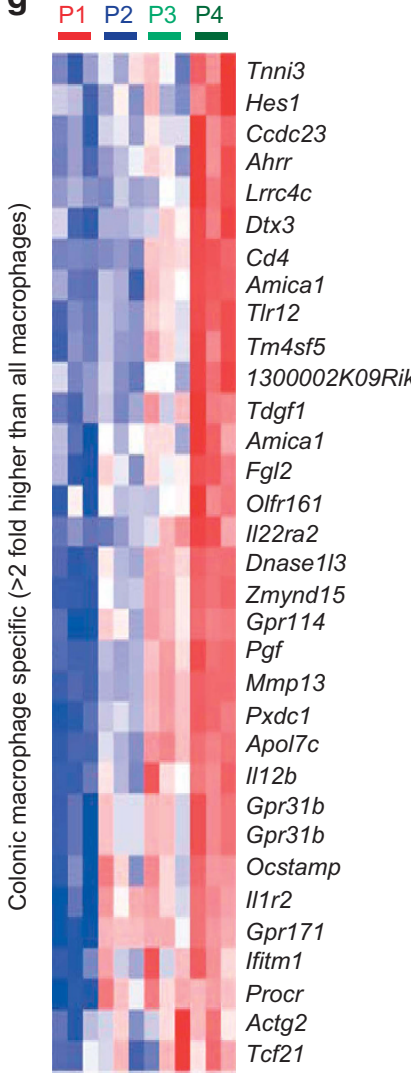

h
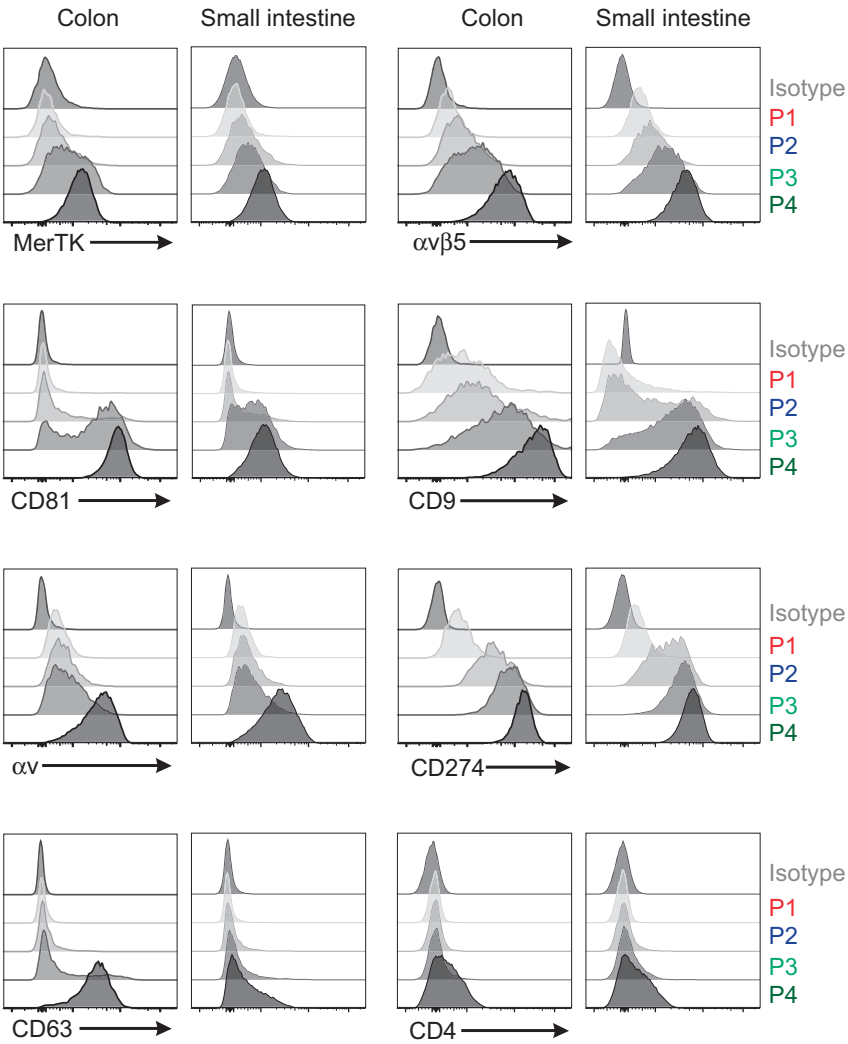
above as being expressed at more than equal to twofold higher levels by colonic $\mathrm{m} \phi$ than in any other tissue $\mathrm{m} \phi$ (Figure $\mathbf{1 g}$ and Supplementary Figure 1b), thus identifying a signature of monocyte differentiation that is specific to the colonic mucosa. Flow cytometry confirmed the increasing expression of surface proteins corresponding to a number of genes regulated during the maturation process, with comparable changes being observed in the colon and small intestine (Figure $\mathbf{1 h}$ and Supplementary Figure 2). However, this also showed that although some receptors such as $\alpha \mathrm{v} \beta 5$ integrin, CD274, and CD9 were upregulated progressively through the monocyte waterfall, others such as CD63 and CD4 only appeared on fully mature CX3CR $1^{\text {hi }} \mathrm{m} \phi$ (Figure 1h). Thus, the changing expression of the genes that mark intestinal $\mathrm{m} \phi$ differentiation is not an entirely synchronous process.
Together these findings support the idea that tissue specific signals drive intestinal $\mathrm{m} \phi$ to acquire a specific homeostatic signature as they differentiate from monocytes.

\section{The colonic environment shapes a tissue-specific program of monocyte-m $\phi$ differentiation}

To explore the mechanisms involved in this specific developmental process in the colon, we repeated our analysis of different tissue $m \phi$, this time focussing on the 1,004 genes that were significantly up- or downregulated during the transition from monocytes to resident $\mathrm{m} \phi$ in the colon (Supplementary Table 1). In this way, we aimed to identify those genes whose regulation was selective for differentiation in the colon, as opposed to being part of generic $\mathrm{m} \phi$ development. This approach showed that colonic $\mathrm{m} \phi$ cluster closely with skin


b

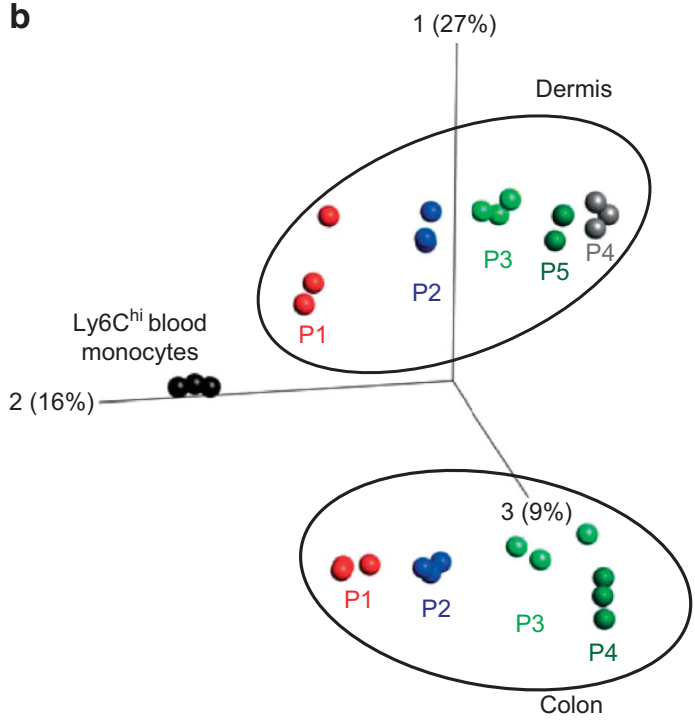

d

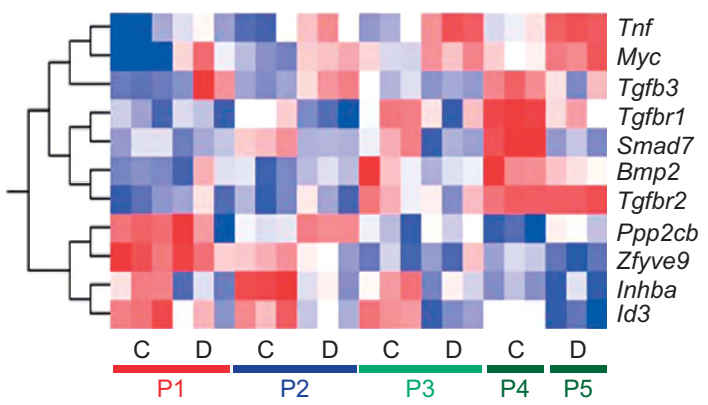

Figure 2 Comparative transcriptomic analysis of monocyte-macrophage differentiation in the colonic mucosa and dermis. (a) Hierarchical cluster analysis of mature colonic macrophages $\left(\mathrm{CD} 11 \mathrm{~b}{ }^{+} \mathrm{CD} 64^{+} \mathrm{Ly}_{6 \mathrm{C}^{-}} \mathrm{MHCll}{ }^{+} \mathrm{CX} 3 \mathrm{CR} 1^{\mathrm{hi}} ; \mathrm{P} 4\right)$ and macrophages from the lung, brain, bone marrow, spleen, peritoneal cavity, and dermis based on the 1,004 genes that show a greater than twofold increase in expression between P1 and P4 in the colon (Supplementary Table 1). (b) Principal component analysis (PCA) of gene expression by Ly6 $\mathrm{C}^{\text {hi }}$ blood monocytes, $\mathrm{P} 1-\mathrm{P} 4$ subsets from steady state colon and P1-P5 subsets from steady state dermis identified as in Supplementary Figure 2. Numbers in parentheses indicate the relative scaling of the principal variables (ANOVA; $P_{\mathrm{Raw}} \leq 0.05 ; P_{\mathrm{Adj}} \leq 0.14$ ). (c) Overlapping and differentially expressed genes that are significantly upregulated (upper panel) and downregulated (lower panel) between P1 and P4 in the colon and P1 and P5 in the dermis. (Student's $t$-test; $P \leq 0.05$; fold change $\geq 2.0$; comparing colonic P1 vs P4 and dermal P1 vs P5, respectively). (d) TGF $\beta$ R pathway-associated genes regulated during colonic macrophage differentiation identified by Gene Set Enrichment Analysis expressed by P1-P4 subsets in colon (C) and P1-P5 subsets in the dermis (D). (KEGG Database; $P_{\text {Raw }}$ $\left.=0.0031 ; P_{\text {Adj }} \leq 0.0107\right)$. 
dermal and lung interstitial $\mathrm{m} \phi$ (Figure 2a), populations that are also replenished by BM-derived monocytes. ${ }^{10,14}$ Indeed a "monocyte waterfall" containing short-lived P1, P2, and P3 subsets is also present in the steady state dermis (Supplementary Figure 3a). ${ }^{10}$ In contrast to the colon, the mature $\mathrm{m} \phi$ compartment of the dermis contains both $\mathrm{MHCII}^{-}$ (designated dermal P4) and $\mathrm{MHCII}^{+}$(dermal P5) cells. We reasoned that transcriptional differences between the various stages within the monocyte-m $\phi$ continuum in the colon and dermis could reveal factors specific to the colonic environment. Principal component analysis of the individual subsets within the "monocyte waterfall" from the colon and the dermis showed progressively increasing transcriptional distance between each phenotypically defined stage and Ly6C $\mathrm{C}^{\text {hi }}$ blood monocytes, consistent with a putative linear relationship between each subset within its own tissue (Figure 2b). Importantly, however, the equivalent subsets in colon and dermis became increasingly separate as they progressed through development, suggesting that a tissue-dependent program determined the eventual outcome of monocyte differentiation.

Although a substantial number of genes showed significant changes in expression between newly arrived monocytes and mature $\mathrm{MHCII}^{+} \mathrm{m \phi}$ in both the colon and dermis $(1,004$ and 838 genes, respectively; Supplementary Table 2), only 240 of the upregulated and 147 of the downregulated genes were common to the two tissues (Figure 2c). Because the developmental origin and relationship of the $\mathrm{MHCII}^{-}$and $\mathrm{MHCII}^{+} \mathrm{m \phi}$ in the dermis is unclear, and there is no analogous $\mathrm{MHCII}^{-}$population in the adult colon, we omitted dermal $\mathrm{MHCII}^{-} \mathrm{m} \phi$ from these analyses. Among the shared downregulated genes were those involved in extravasation of monocytes such as Sell (CD62L), Ly6c1 (Ly6C), Itgb7 ( $\beta 7$ integrin), and proinflammatory molecules like Trem 1. Among the shared upregulated genes were Il10, H2-M2, Mrc1 (CD206), Mertk, Gas6, C1qb, C1qc, C1qa, Cd163, and Itgax (Supplementary Table 2). Three hundred and seventy-three genes were selectively upregulated by maturing monocytes in the colon, and 163 of these genes were expressed by twofold or more by fully mature colonic $\mathrm{m} \phi(\mathrm{P} 4)$ compared with their $\mathrm{MHCII}^{+}$ (P5) equivalents in the dermis (Figure 2c, upper panel, Supplementary Table 2). These genes seem to comprise a cassette selectively imprinted in mature $\mathrm{m} \phi$ by the colonic tissue environment (Supplementary Table 2).

Gene Set Enrichment Analysis highlighted the TGF $\beta R$ signaling pathway as a potential candidate for driving the colonic differentiation process. Genes belonging to this pathway were enriched among the 1,004 genes that define $\mathrm{m} \phi$ maturation in the colon (Supplementary Table 3). A set of these genes was also amongst those upregulated selectively during the differentiation of monocytes into mature $\mathrm{m} \phi$ in the colon but not in the dermis. These included Tgfbr1, Bmp2, Smad7, and $T g f b 3$ (Figure 2d). Together these findings indicate that the tissue specific properties of colonic $\mathrm{m} \phi$ reflect the outcome of selective differentiation of monocytes, driven by the local environment and that this process may involve TGF $\beta R$ signaling.
TGF $\beta R 1$ signaling regulates monocyte accumulation in the colon

To investigate whether TGF $\beta$ R signaling contributed to colonic m $\phi$ development in vivo, we examined mice that lack Tgfbr1 on $\mathrm{CD}_{11 \mathrm{c}^{+}}$cells using CD11c-Cre-Tgfbr $1^{\mathrm{fl} / \mathrm{fl}}$ mice, as in our hands, most colonic m $\phi$ express CD11c at significant levels. ${ }^{9}$ These mice were maintained on a $\operatorname{Rag} 1^{-1-}$ background (Figure 3a) to circumvent the fatal multi-organ inflammation that occurs due to Cre recombinase activity in a small subset of T cells in CD11c-Cre$T g f b r 1^{\mathrm{f} / \mathrm{fl}}$ mice \{Bain, Montgomery et al., unpublished observations\}. Histology of the colonic tissue isolated from CD11c-Cre-Tgfbr $1^{\mathrm{f} / \mathrm{fl}} \mathrm{Rag}^{-/-}$mice confirmed the absence of intestinal inflammation (data not shown). Analysis of CD11cCre-Rosa26-LSL-eYFP reporter mice confirmed efficient CD11c driven Cre recombinase activity in both $\mathrm{CD}^{-} \mathrm{DC}$ and $\mathrm{CD}^{+}{ }^{+} \mathrm{Ly} 6 \mathrm{C}^{-} \mathrm{MHCII}{ }^{+} \mathrm{m} \phi$ in the colon, the latter being the equivalent of the $\mathrm{P} 3+\mathrm{P} 4$ subsets defined in $\mathrm{C} x 3 \mathrm{cr} 1^{+/ \mathrm{GFP}}$ mice. In contrast, there was little or no Cre activity in $\mathrm{Ly}_{6 \mathrm{C}}{ }^{\text {hi }} \mathrm{MHCII}^{-} \mathrm{P} 1$ monocytes, their $\mathrm{Ly}_{6 \mathrm{C}} \mathrm{MHCII}^{+} \mathrm{P} 2$ descendants or in other $\mathrm{CD} 11 \mathrm{c}^{\mathrm{lo} /-}$ cells in the mucosa including eosinophils (Supplementary Figure 4b, c). Analysis of CD11c-Cre-Tgfbr $1^{\mathrm{fl} / \mathrm{ll}} \mathrm{Rag} 1^{-/-}$ mice revealed a trend towards more $\mathrm{Ly}_{6 \mathrm{C}}{ }^{+} \mathrm{MHCII}^{-} \mathrm{P} 1$ and Ly6C $^{+} \mathrm{MHCII}^{+} \mathrm{P} 2$ cells, together with significantly fewer mature $\mathrm{Ly}_{6 \mathrm{C}}^{-} \mathrm{MHCII}{ }^{+} \mathrm{m} \phi$ among $\mathrm{CD}^{+}{ }^{+}$cells in the colon of $\mathrm{Cre}^{+}$compared with $\mathrm{Cre}^{-}$mice (Figure $\mathbf{3 b}$ and $\mathbf{c}$ ). To assess the impact of TGF $\beta$ R deficiency in a competitive environment, we next generated mixed BM chimeric mice. Lethally irradiated $\mathrm{CD} 45.1^{+} / \mathrm{CD} 45.2^{+}$recipients were reconstituted with a mixture of $\mathrm{BM}$ from wild-type (WT) $\left(\mathrm{CD} 45.1^{+}\right)$and $\mathrm{Cre}^{-}$or $\mathrm{Cre}^{+}$ $T g f b r 1^{\mathrm{fl} / \mathrm{fl}}\left(\mathrm{CD} 45.2^{+}\right)$mice (Figure 3d). Under these conditions, WT and both types of $T g f b r 1^{\mathrm{fl} / \mathrm{fl}} \mathrm{BM}$ were able to generate monocyte-m $\phi$ subpopulations in the colonic mucosa (Supplementary Figure 5a). However, the $\mathrm{Cre}^{+} \mathrm{BM}$ showed a small, but significant reduction in the generation of mature Ly6C $^{-} \mathrm{MHCII}^{+}$(P3/P4) m $\phi$ compared with WT BM, a competitive disadvantage consistent with the presence of CD11c and therefore active Cre recombinase expression on these mature $m \phi$. Analysis of the monocyte waterfall in the mixed BM chimeras showed that there were significantly higher frequencies of $\mathrm{P} 1$ and $\mathrm{P} 2$ cells, together with fewer $\mathrm{Ly}_{6 \mathrm{C}}{ }^{-} \mathrm{MHCII}{ }^{+}$ (P3/P4) $\mathrm{m} \phi$ in the colon of WT:Cre ${ }^{+}$chimeras compared with their WT:Cre ${ }^{-}$controls (Figure $3 \mathbf{e}$ and $\mathbf{f}$ ). Interestingly, these changes in the monocyte-m continuum were not due to an intrinsic loss of TGF $\beta \mathrm{R} 1$ signaling, as both Tgfbr $1^{\mathrm{f} / \mathrm{fl}}$ - and WTderived P1 and P2 cells were over-represented in WT:Cre ${ }^{+}$ chimeras (Supplementary Figure 5b).

To assess whether these effects were due to deletion of TGF $\beta R 1$ on cells of the monocyte/m $\phi$ lineage as opposed to other $\mathrm{CD}_{11 \mathrm{c}^{+}}$cells, we generated BM chimeras in which complete TGF $\beta$ R1 deficiency was restricted to this lineage. Lethally irradiated CD $45.1^{+} / \mathrm{CD} 45.2^{+}$recipients were reconstituted with a 50:50 mix of BM from $\mathrm{Ccr} 2^{-l-}\left(\mathrm{CD} 45.1^{+}\right)$and $\mathrm{Cre}^{-}$or Cre ${ }^{+} \mathrm{Tgfbr} 1^{\mathrm{fl} / \mathrm{fl}}\left(\mathrm{CD} 45.2^{+}\right)$mice (Figure 3g). Consistent with our previous findings that intestinal $\mathrm{m} \phi$ require constant replenishment by CCR2-dependent precursors, ${ }^{9,18}$ the colonic m $\phi$ compartment in these animals was derived almost 


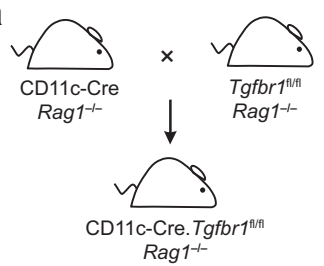

d

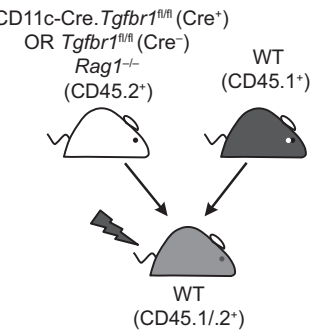

g

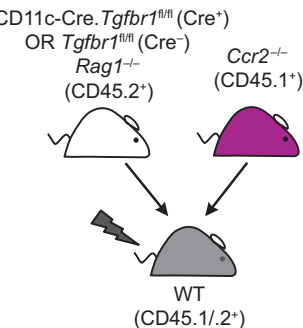

b

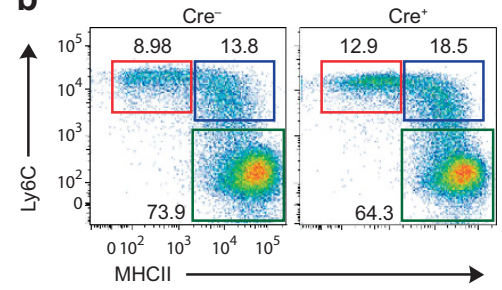

e

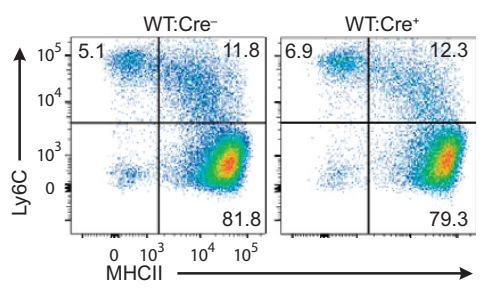

h

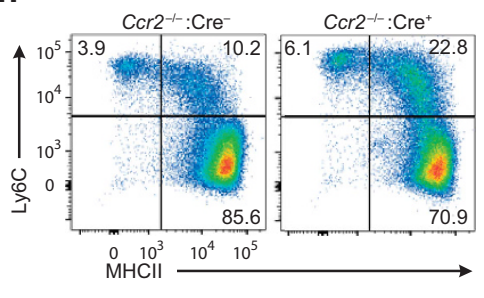

C
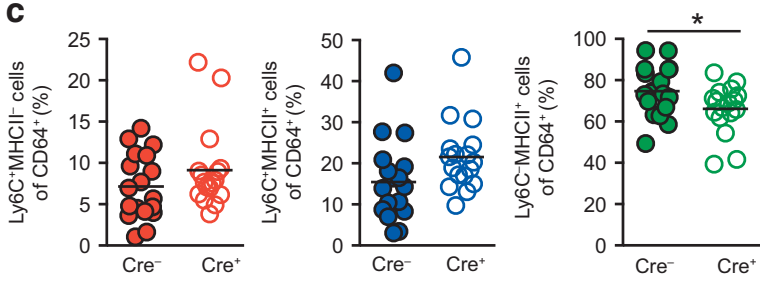

f
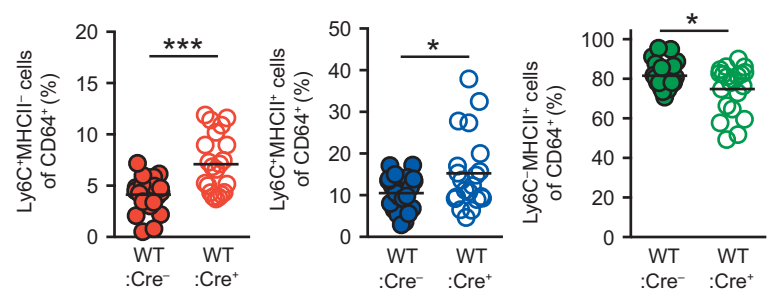

i

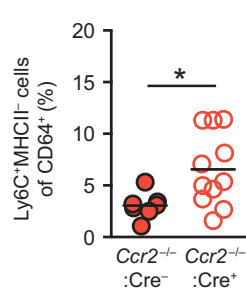

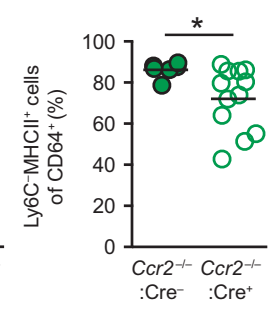

Figure 3 TGF $\beta R 1$ signaling regulates monocyte accumulation in the colon. (a) Schematic representation of the CD11c-Cre. Tgfbr $1^{\mathrm{fl} / \mathrm{fl}}$ strain.\&\#8232;(b)

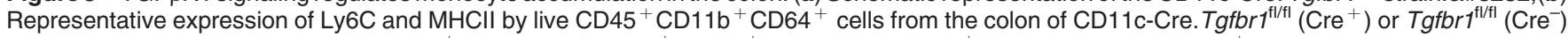

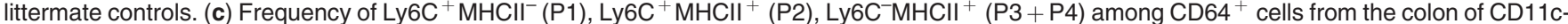
Cre. Tgfbri $1^{\mathrm{fl} / \mathrm{fl}}\left(\mathrm{Cre}^{+}\right)$, or Tgfbri $1^{\mathrm{fl} / \mathrm{fl}}\left(\mathrm{Cre}^{-}\right)$littermate controls. Symbols represent individual animals and horizontal bar is the mean of $n=17\left(\mathrm{Cre}^{+}\right)$or 18 $\left(\mathrm{Cre}^{-}\right)$mice pooled from five independent experiments. ${ }^{*} P<0.05$ as determined by Student's $t$-test. (d) Schematic representation of the generation of

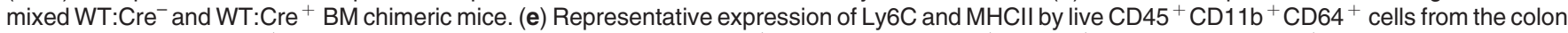

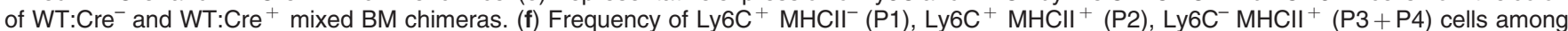
$\mathrm{CD}^{+} 4^{+}$cells from the colon of WT:Cre ${ }^{-}$, and WT:Cre ${ }^{+}$BM chimeric mice. Symbols represent individual animals and horizontal lines are the means of 21 mice per group and are pooled from five independent experiments. ${ }^{\star} P<0.05,{ }^{\star \star} P<0.01,{ }^{\star \star \star}{ }^{*} P<0.001$ as determined by Student's $t$-test. (g) Schematic representation of the generation of mixed $\mathrm{Ccr}^{-1-}: \mathrm{Cre}^{-}$and $\mathrm{Ccr}^{-l-}: \mathrm{Cre}^{+} \mathrm{BM}$ chimeric mice. (h) Representative expression of Ly6C and MHCIl by live $\mathrm{CD} 45^{+} \mathrm{CD} 11 \mathrm{~b}^{+} \mathrm{CD} 64^{+}$cells from the colon of $\mathrm{Ccr} 2^{-1-}: \mathrm{Cre}^{-}$and $\mathrm{Ccr2}{ }^{-1-}: \mathrm{Cre}^{+}$mixed BM chimeras. (i) Frequency of Ly6C ${ }^{+} \mathrm{MHClI}^{-}(\mathrm{P} 1)$,

$\mathrm{Ly} 6 \mathrm{C}^{+} \mathrm{MHClI}^{+}(\mathrm{P} 2), \mathrm{Ly} \mathrm{C}^{-} \mathrm{MHClI}^{+}(\mathrm{P} 3+\mathrm{P} 4)$ cells among CD64 ${ }^{+}$cells from the colon of $\mathrm{Ccr}^{-1-}: \mathrm{Cre}^{-}$and $\mathrm{Ccr}^{-1-}{ }^{-} \mathrm{Cre}^{+}$mixed BM chimeras. Data are from seven $\left(\mathrm{CCr}^{-1-}: \mathrm{Cre}^{-}\right)$or $11\left(\mathrm{CCr}^{-}{ }^{-}: \mathrm{Cre}^{+}\right)$mice per group and are pooled from $3-4$ independent experiments. ${ }^{*} P<0.05$ as determined by Student's $t$-test.

Figure 4 TGF $\beta$ R1-dependent signaling shapes colonic macrophage differentiation. (a) Volcano plot comparing the expression of genes that show a greater than twofold change in expression between P1 and P4 in the colon (Supplementary Table 1) by CD11b ${ }^{+} \mathrm{CD}_{6}{ }^{+} \mathrm{Ly}_{6 \mathrm{C}}{ }^{-} \mathrm{MHCII}{ }^{+}(\mathrm{P} 3+\mathrm{P} 4)$ macrophages from CD11c-Cre. Tgfbr $1^{\mathrm{fl} / \mathrm{fl}}\left(\mathrm{Cre}^{+}\right)$or $\mathrm{Tgfbr}^{\mathrm{fl} / \mathrm{fl}}\left(\mathrm{Cre}^{-}\right)$littermate controls. Selected genes with fold change $\geq 1.5$ and $P_{\mathrm{Raw}} \leq 0.05$ are highlighted, whereas genes with fold-change of $<1.5$ are shown in gray (see also Supplementary Table 2). The dashed line represents the border for

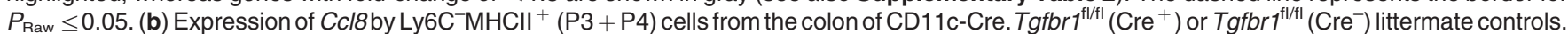
Data are the mean normalized probe intensity +1 s.d. taken from the microarray analysis shown in a with three biological replicates per group. ${ }^{\star} P<0.05$

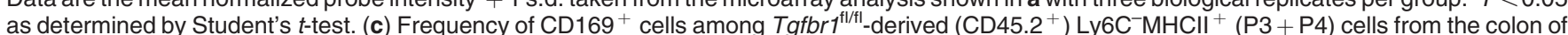
WT:Cre ${ }^{-}$and WT:Cre ${ }^{+}$mixed BM chimeras. (d) Frequency of $T$ gfbr $1^{\mathrm{fl} / \mathrm{fl}}$-derived CD169 ${ }^{+} \mathrm{Ly}_{6 \mathrm{C}^{-}} \mathrm{MHClI}^{+}(\mathrm{P} 3+\mathrm{P} 4)$ cells presented as a ratio of their WTderived counterparts from the same colon of WT:Cre ${ }^{-}$and WT:Cre ${ }^{+}$mixed BM chimeras. Bars represent the means of six mice per group + s.d. and are pooled from two independent experiments. ${ }^{* *} P<0.01$, ${ }^{* * * *} P<0.0001$ as determined by Student's $t$-test. (e) Quantitative RT-PCR analysis of Tgfbr1,

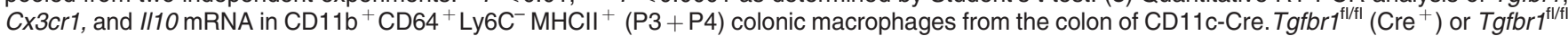
$\left(\mathrm{Cre}^{-}\right)$littermate controls. Data are from one experiment with three biological replicates. ${ }^{\star} P<0.05,{ }^{* \star} P<0.01$ as determined by Student's $t$-test. (f) Flow cytometric validation of $\alpha \mathrm{v} \beta 5, \alpha \mathrm{v}$, and CD9 expression by P1, P2, and P3 + P4 cells from the colon and small intestine of CD11c-Cre. Tgfbr $1^{\mathrm{fl} / \mathrm{fl} l}\left(\mathrm{Cre}{ }^{+}\right.$) or $\mathrm{Tgfbr}^{\mathrm{fl} / \mathrm{fl}}$ (Cre ${ }^{-}$) littermate controls (upper panels). MFI are shown for individual animals and horizontal lines represent the mean (lower panels). Data are from one experiment (CD9 for colon and small intestine, $\alpha v \beta 5, \alpha v$ for small intestine) or pooled from two independent experiments ( $\alpha v \beta 5$, $\alpha v$ for colon) with 2-7 mice per group. ${ }^{* \star} P<0.01$ determined by Mann-Whitney test. (g) Expression of TGF $\beta R$-dependent genes in a above by the P1-P4 subsets from the colon (C) or P1-P5 subsets from the dermis (D). The genes listed are those expressed at least twofold higher in colon P4 compared with dermal P5 cells. (h) Clustering analysis of tissue macrophage populations based on the TGF $\beta$ R-dependent module as in a above. The genes listed are those from the highlighted cluster that show overlapping expression between microglia and colonic macrophages. Genes highlighted in red represent genes that have been reported previously as 'microglia specific'. ${ }^{24,26}$ 
completely from the $T g f b r 1^{\mathrm{f} / / \mathrm{fl}}$ donor (Supplementary Figure 5c). In contrast, CCR2-independent cells such as eosinophils were derived equally from both BM sources (Supplementary Figure 5c). The $\mathrm{Ccr} 2^{-1-}: \mathrm{Cre}^{+}$chimeras recapitulated the increased frequencies of immature P1 and P2 cells, and fewer $\mathrm{Ly}^{-} \mathrm{C}^{-} \mathrm{MHCII}{ }^{+}$(P3/P4) m $\phi$ (Figure $\mathbf{3 h}$ and i). As in the intact CD11c-Cre-Tgfbr $1^{\mathrm{f} / / \mathrm{f}} \mathrm{Rag} 1^{-/-}$mice, there was no histological evidence of intestinal inflammation in the $\mathrm{Ccr}^{-1-}: \mathrm{Cre}^{+}$chimeric mice, indicating this was not responsible for the changes in the waterfall (Supplementary Figure 5d). a
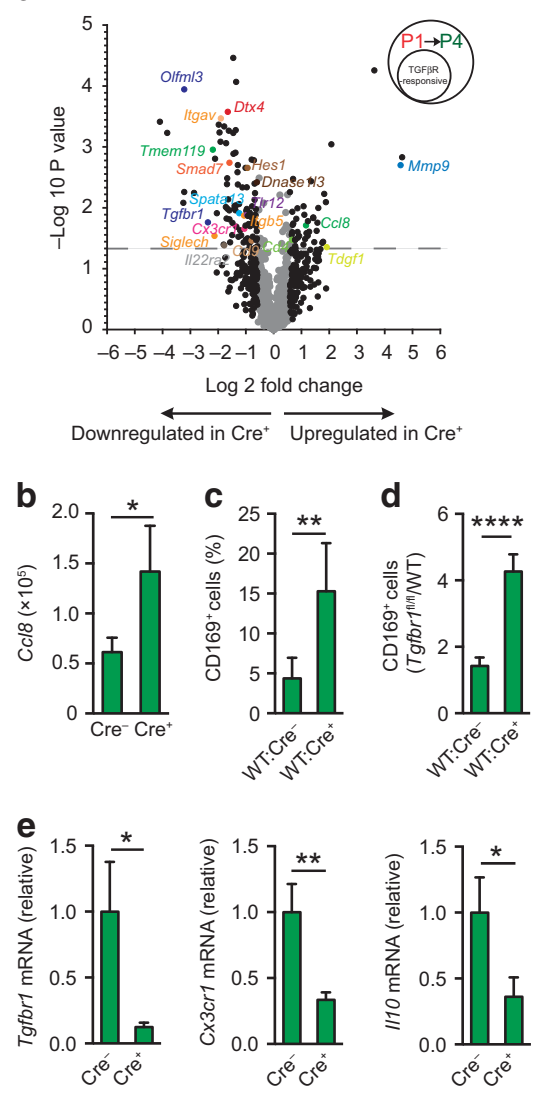

\section{g}

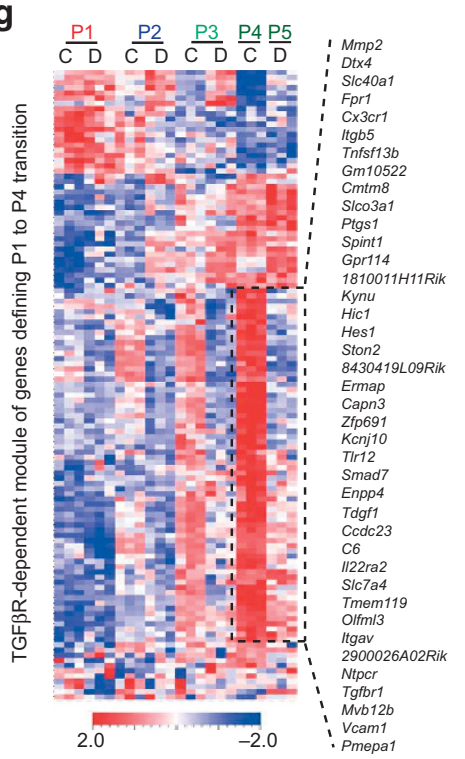

f
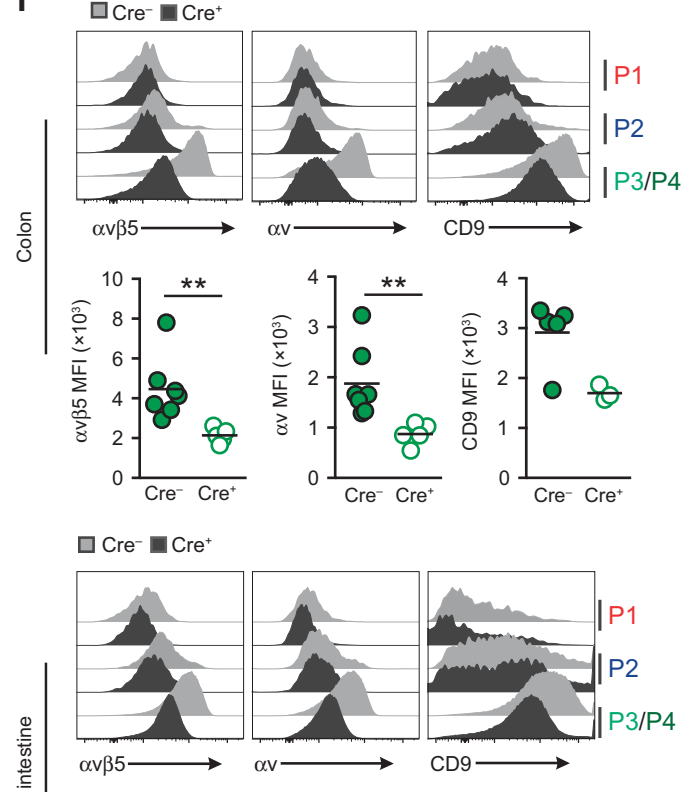

के



h

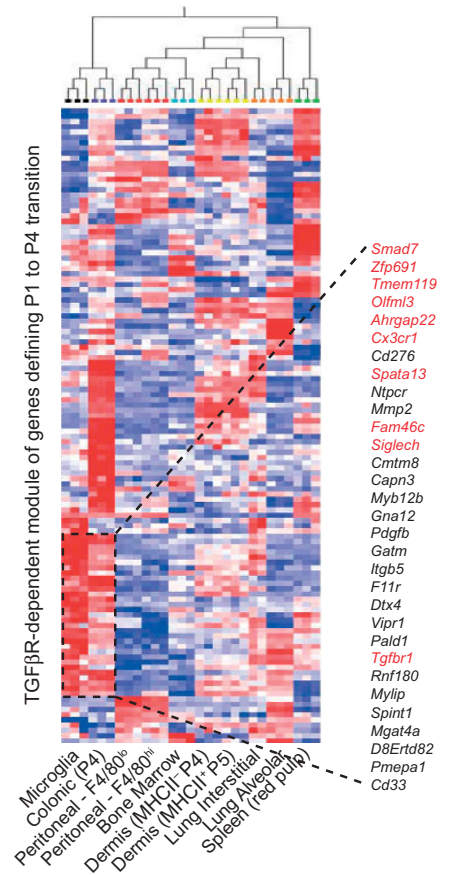


Dendritic cell subsets were present in comparable frequencies in the two groups of CD11c-Cre-Tgfbr1 $1^{f l f l} \times C \mathrm{cr} 2^{-/-}$chimeric mice (Supplementary Figure 5e). Thus the dysregulated monocyte-m continuum in the absence of TGF $\beta$ R-mediated signaling in $\mathrm{CD}_{11 \mathrm{c}^{+}}$cells is due to an effect on mature $\mathrm{m} \phi$, rather than secondary to changes in the DC compartment.

\section{TGF $\beta R$ 1-dependent signaling shapes intestinal $\mathrm{m} \phi$ differentiation}

To assess the impact of Tgfbrl deficiency on colonic $\mathrm{m} \phi$ differentiation in more detail, we compared the transcriptome of mature $\mathrm{CD}_{64}{ }^{+} \mathrm{Ly}_{6} \mathrm{C}^{-} \mathrm{MHCII}{ }^{+} \mathrm{m} \phi$ from $\mathrm{Cre}^{-}$and Cre ${ }^{+}$mice, focussing on the 1,004 genes that we found to define monocyte to $\mathrm{m} \phi$ differentiation in the colon (Supplementary Table 1 online). Of these, 115 were differentially expressed by at least 1.5-fold in $\mathrm{Cre}^{+}$compared with $\mathrm{Cre}^{-}$mice (Figure 4a and Supplementary Table 4). Notably, among those upregulated was the monocyte chemoattractant $C c l 8$, which could explain the increased abundance of P1 and P2 we observed in CD11c-Cre$T g f b r 1^{\mathrm{fl} / \mathrm{fl}} \mathrm{Ragl}^{-1-}$ and both BM chimeric systems (Figure 4a and b). Indeed CCL8 is reported to be preferentially produced by $\mathrm{CD}_{169}{ }^{+}$mature $\mathrm{m} \phi$ in the colon ${ }^{25}$ and we observed increased frequencies of $\mathrm{CD} 169^{+} \mathrm{m} \phi$ among $\mathrm{CD} 64^{+} \mathrm{Ly}^{+} \mathrm{C}^{-} \mathrm{MHCII}^{+} \mathrm{m} \phi$ from WT:Cre ${ }^{+}$mice compared with control WT:Cre ${ }^{-}$mice (Figure 4c). Analysis of WT:Cre ${ }^{+}$mice confirmed that the increased abundance of $\mathrm{CD} 169^{+}$cells was due to loss of cellintrinsic TGF $\beta$ R signaling (Figure 4d).

Among those genes downregulated in the absence of TGF $\beta R 1$ signaling were Hes1, Il22ra2, and Tlr12, genes we had found to be selectively enriched in colonic $m \phi$ compared with all other tissue $\mathrm{m} \phi$ (Figure 4a, Supplementary Figure 1b). mRNA transcripts for Itgav, Itgb5, Cd9, and Cx3cr1 were also expressed at significantly lower levels in mature $\mathrm{Cre}^{+} \mathrm{m} \phi$, findings that were confirmed by real time-qPCR or flow cytometric analysis of for $\alpha_{v}, \alpha_{v} \beta_{5}$, and CD9 expression by small intestinal and colonic $\mathrm{m} \phi$ (Figure $4 \mathrm{e}$ and f). Notably, real time-qPCR analysis showed lower levels of Illo mRNA transcripts in Tgfbr $1^{-1-} \mathrm{m} \phi$ compared with their Tgfbr1-sufficient counterparts (Figure 4e). We then used the group of genes that differed between $\mathrm{Cre}^{+}$and $\mathrm{Cre}^{-} \mathrm{m} \phi$ to interrogate the differentiation continuums in WT colon and dermis. This identified a set of TGF $\beta$ R-dependent genes that appeared to define the colon specific differentiation of monocytes (Figure 4g). Interestingly, clustering of all tissue $\mathrm{m} \phi$ based on the TGF $\beta$ R-dependent genes revealed similarity between colonic $\mathrm{m} \phi$ and microglia (Figure $4 \mathbf{h}$ ). Indeed, several genes reported previously to be 'microglia-specific' (for example, Tmem119, Olfml3, Spata13, and Siglech) ${ }^{24,26}$ were highly expressed by colonic $\mathrm{m} \phi$ (Figure $4 \mathbf{a}$ and $\mathbf{h}$ ).

Thus TGF $\beta R$ signaling is critical for the acquisition of the characteristic traits of mature homeostatic intestinal $\mathrm{m} \phi$ as they differentiate from monocytes.

TGF $\beta$ and IL10 imprint non-overlapping features of colonic $\mathbf{M} \phi$ One of the most characteristic features of mature intestinal $\mathrm{m} \phi$ is that during their development from monocytes they become hyporesponsive to stimulation with TLR ligands. ${ }^{8,21,27}$ Although IL10 receptor signaling has been shown to be involved in this
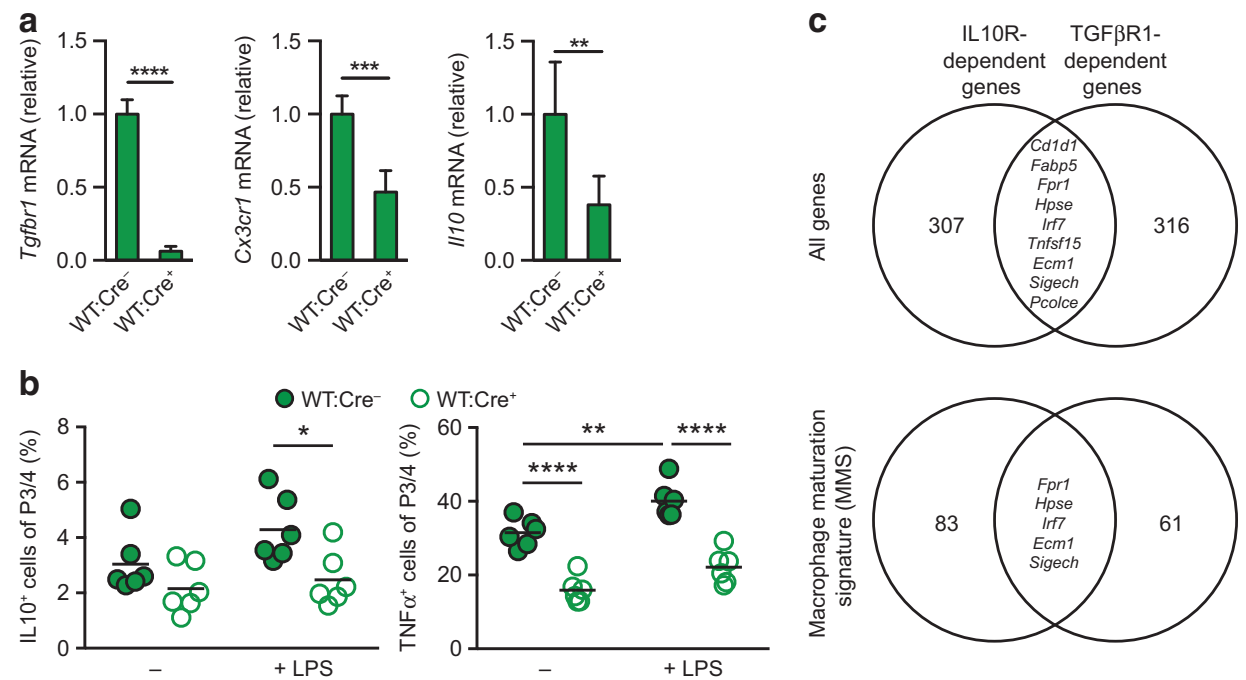

Figure 5 TGF $\beta$ and IL10 imprint non-overlapping features of colonic macrophages. (a) Quantitative RT-PCR analysis of Tgfbr1, Cx3cr1, and I/10mRNA

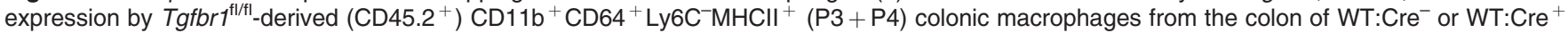
mixed BM chimeric mice. Data are from one experiment with five biological replicates. ${ }^{* \star} P<0.01,{ }^{* * *} P<0.001,{ }^{* * *} P<0.0001$ as determined by Student's $t$-test. (b) Expression of IL10 (left panel) or TNF $\alpha$ (right panel) by Tgfbr $1^{\mathrm{fl} / \mathrm{fl}}$-derived (CD45.2 ${ }^{+}$) P3/4 colonic macrophages from the colon of WT:Cre ${ }^{-}$or $\mathrm{WT}: \mathrm{Cre}^{+}$mixed BM chimeric mice assessed by intracellular cytokine staining following $4.5 \mathrm{~h}$ culture in the presence $(+$ LPS $)$ or absence $(-)$ of LPS. Symbols represent individual animals and the horizontal lines are the means of six mice per group and are pooled from two independent experiments. ${ }^{\star} P<0.05,{ }^{* \star} P<0.01,{ }^{* * \star *} P<0.0001$ as determined by Student's $t$-test. (c) Total mRNA transcripts (upper panel) and mRNA transcripts that show a greater than twofold change in expression between P1 and P4 in the colon (lower panel; see also Supplementary Table 1) that show at least twofold difference between I/10ra ${ }^{+1+}$ and II10ra ${ }^{-1-}$ colonic macrophages (IL10R-dependent ${ }^{28}$ ) or between Tgfbr1 $1^{+/+}$and Tgfbr1 $1^{-1-}$ colonic macrophages (TGF $\beta R 1$-dependent) (Student's $t$-test; $P \leq 0.05$; fold change $\geq 2$.0). Genes named in the overlapping regions are impacted by both IL10R and TGF $\beta$ R1 deficiency. 
in vivo, ${ }^{28-31}$ experiments with human $\mathrm{m} \phi$ have suggested that it may be induced by TGF $\beta$ in vitro. ${ }^{19,32}$ To investigate this role of TGF $\beta R$ signaling in vivo, we assessed cytokine production by $\mathrm{m} \phi$ from the colon of WT:Cre ${ }^{-} / \mathrm{Cre}^{+}$mixed BM chimeric mice in the presence and absence of TLR4 ligation by lipopolysaccharide (LPS). This revealed no changes in TLR4 responsiveness, as cytokine production was increased to a similar extend by LPS stimulation in $\mathrm{Cre}^{-}$and $\mathrm{Cre}^{+} \mathrm{m \phi}$ (Figure 5b). However, as in intact CD11c-Cre-Tgfbr1 ${ }^{\mathrm{t} / \mathrm{ll}} \mathrm{Rag1}^{-1-}$ mice, resting colonic $\mathrm{m} \phi$ derived from Tgfbr1 ${ }^{-1-}$ BM had reduced levels of mRNA for IL10 compared with their $\mathrm{Tgfbr1} \mathrm{I}^{+/+}$-derived counterparts and this was confirmed by intracellular cytokine staining (Figure $\mathbf{5 a}$ and $\mathbf{b}$ ). Interestingly, resting $T g f b r 1^{-1-}$-derived $\mathrm{m} \phi$ also expressed lower levels of TNF $\alpha$ (tumor necrosis factor $\alpha$ ) protein (Figure 5b). These differences in IL10 and TNF $\alpha$ production were maintained after stimulation via TLR4 (Figure 5b).

These results indicate that although TGF $\beta$ R and IL10Rmediated signaling can both influence the behavior of resident intestinal $\mathrm{m} \phi$ in vivo, their effects appear to be quite distinct. To study this in more detail, we compared the global transcriptome of TGF $\beta R$-deficient $m \phi$ with that of a recently published transcriptome from IL10R-deficient $m \phi .^{28}$ When compared with their control populations, 316 and 325 genes were expressed at significantly different levels by IL10R- and TGF $\beta R 1$-deficient $m \phi$, respectively. However, only nine of these were affected by both IL10R and TGF $\beta$ R 1deficiency, and this was reduced to five genes when we focused on the 1,004 genes defining the transition from monocytes to resident $\mathrm{m} \phi$ in the colon (Figure 5c).

Thus, IL10 and TGF $\beta$ act in concert to imprint largely nonoverlapping phenotypic and functional characteristics of mature $\mathrm{m} \phi$ in the colonic mucosa.

\section{DISCUSSION}

Tissue $m \phi$ are highly heterogeneous and their differentiation is determined by tissue-specific combinations of individual cytokines, transcription, and growth factors. ${ }^{7,15,22,23,26}$ Here we show that mature $\mathrm{m} \phi$ in steady state colon progressively acquire a specific signature as they differentiate locally from classical Ly6 $\mathrm{C}^{\text {hi }}$ monocytes via a process that is determined to a substantial degree by intrinsic TGF $\beta$-mediated signaling.

By identifying a module of genes that is expressed by colonic $\mathrm{m} \phi$ but not by mature $\mathrm{m} \phi$ from other tissues, we extend previous findings that intestinal $\mathrm{m} \phi$ possess a distinctive transcriptional and epigenetic landscape. ${ }^{15}$ To the best of our knowledge, this is the first study to perform transcriptional profiling of monocyte-m $\phi$ differentiation in the gut. By doing so, we demonstrate progressive imprinting by the colonic environment, as each stage within the local differentiation continuum became increasingly distinct from the equivalent subsets in dermis that share a classical monocyte precursor. ${ }^{9,10}$ This process must begin rapidly after recruitment of monocytes into the tissue, as newly arrived monocytes in the colon ("P1") were already transcriptionally distinct from their counterparts in both blood and dermis. This is consistent with our earlier findings that adoptively transferred Ly6 $\mathrm{C}^{\text {hi }}$ monocytes enter the colonic mucosa and change in phenotype within $24 \mathrm{~h}$ after transfer. ${ }^{8}$ The mechanisms involved in this early acquisition of tissue specificity are unknown. However, the process of crossing the endothelial barrier can itself induce phenotypic and genetic changes in monocytes ${ }^{33}$ and the consequences of this could vary depending on the anatomical site. Other sources of such factors could be stromal cells in the vicinity of blood vessels and it would be important to explore the tissue specificity of such processes in future. Alternatively, we cannot rule out the possibility that the BM monocyte compartment may be heterogeneous, with individual subsets already imprinted to migrate to specific tissues, but to date, this possibility has not been explored directly.

Important clues to the potential homeostatic roles of intestinal $\mathrm{m} \phi$ emerged from our comparative analysis of colonic and dermal $\mathrm{m} \phi$ development. In particular, genes encoding receptors for apoptotic cells showed progressive upregulation as monocytes matured and while some of these were common to both sites (for example, C1q, Mer, and CD36), others (for example, $\alpha_{v} \beta_{5}$ integrin and Axl) were selectively enriched during colonic $\mathrm{m} \phi$ development. $\alpha_{\mathrm{v}} \beta_{5}$ integrin has an indispensable role in removing effete photoreceptor cells from the retina ${ }^{34}$ and mice with LysM-driven deletion of integrin $\alpha_{\mathrm{v}}$ develop spontaneous colitis associated with accumulation of apoptotic cells. ${ }^{35}$ As $\beta_{5}$ is the only partner for the $\alpha_{\mathrm{v}}$ chain expressed by intestinal $\mathrm{m} \phi$ (data not shown), these results suggest that $\alpha_{v} \beta_{5}$ may also be important for maintenance of intestinal homeostasis by myeloid cells. ${ }^{36}$ Together, these findings indicate how this population has been shaped to deal with the specific requirements of its environment. The rapid turnover rate of the intestinal epithelium means that effective clearance of effete cells and remodeling of the underlying extracellular matrix is essential. Colonic $\mathrm{m} \phi$ are perfectly equipped to handle these tasks, being located close to the surface epithelium and possessing all the machinery needed to clear apoptotic epithelial cells and modify the surrounding stroma. Intriguingly, fully differentiated colonic $\mathrm{m} \phi$ also expressed Amical, the gene encoding junctional adhesion molecule-like, a protein that allows leukocytes to adhere to and migrate across tight junctions by binding to the coxsackie and adenovirus receptor expressed by epithelial and endothelial cells. ${ }^{37}$ Our analysis showed that Amical is not expressed to any extent by other $\mathrm{m} \phi$ and given that intestinal CX3CR $1^{+}$ mononuclear phagocytes have been suggested to extend processes into the epithelium to sample the lumen, ${ }^{38,39}$ the ability to form tight junctions may allow intestinal $\mathrm{m} \phi$ to enter the epithelial layer without disruption of the barrier. Importantly, all these activities take place without provoking local inflammation, perhaps reflecting the upregulation of several immunoregulatory mediators and receptors by mature colon $\mathrm{m} \phi$ including Il10, Illr2, Il22ra2, Illsbp, and Cd274, ${ }^{40-43}$ together with progressive downregulation of the pro-inflammatory signaling elements Myd88, Nod2, and Il6.

Recent studies indicated that Tgfbrl is among those genes whose enhancer carries active epigenetic marks in intestinal $m \phi^{15}$ and consistent with this, we identified TGF $\beta$ R-mediated signaling 
as a candidate for controlling colonic $\mathrm{m} \phi$ differentiation. To test this idea, we examined CD11c-Cre.Tgfbr $1^{\mathrm{f} / \mathrm{fl}} \mathrm{Rag} 1^{-/-}$mice, in which mature intestinal $\mathrm{m} \phi$ showed CD11c-driven Cre recombinase activity. All stages of the monocyte waterfall were present in CD11c-Cre.Tgfbr1 ${ }^{\mathrm{I} / \mathrm{l}} \mathrm{Rag1}^{-/-}$mice, suggesting that TGF $\beta$ does not control the recruitment of monocytes or survival of their progeny in the mucosa. However, our transcriptomic analysis identified a role for TGF $\beta$ in the maturation of colonic $m \phi$. Of the genes that define $\mathrm{P} 1$ to $\mathrm{P} 4$ transition, $\sim 10 \%$ were altered in the absence of Tgfbrl, including Cx3crl, whose high expression is a defining feature of terminally differentiated colonic $m \phi{ }^{8,18,44} \mathrm{We}$ cannot exclude the possibility that the transcriptome of $\mathrm{m} \phi$ from the $T g f b r 1^{\mathrm{f} / \mathrm{fl}}$ strains may be influenced by the fact they are bred on a Rag1 $1^{-1-}$ background and hence may be intrinsically distinct from those obtained from the immunocompetent mice that we used to establish the $m \phi$ "signature". However, the fatal multi-organ inflammation that occurs owing to Cre recombinase activity in a small subset of T cells in CD11c-Cre-Tgfbr $1^{\mathrm{t} / / \mathrm{l}}$ mice (Bain, Montgomery et al., unpublished observations) precluded use of these mice for studies of $\mathrm{m} \phi$ function. It was also impossible to target the Tgfbrl deficiency to $\mathrm{m} \phi$ more specifically using, for example, the conditional Cx3cr1-Cre approach, as CX3CR1 itself is downregulated due to Tgfbrl deficiency. However, it is important to note that our studies of Tgfbr1deficient $\mathrm{m} \phi$ used $\mathrm{Cre}^{-}$littermates on the Rag1 ${ }^{-1-}$ background as internal controls, allowing us to identify the TGF $\beta$-dependent effects precisely. Many of the genes in this TGF $\beta$-dependent cassette included those that were upregulated during monocyte maturation in colon, but not in the dermis, consistent with tissue specific imprinting. However, part of this cassette was shared with microglia in the brain, which is known to rely on TGF $\beta$ for their differentiation. ${ }^{26}$ Given that microglia are entirely yolk sacderived, whereas colonic $\mathrm{m} \phi$ are derived from classical monocytes, our findings corroborate recent conclusions that anatomical location, and not developmental origin, is the major determinant of resident $\mathrm{m} \phi$ function. ${ }^{16}$

In addition to these changes in mature $m \phi$, the monocyte waterfall was also disrupted in the absence of Tgfbr1, with more P1 and P2 monocytes, and fewer P $3+4$ cells in all three models we investigated. Importantly, these changes were not secondary to local inflammation, as this was not present in any of the models. Although the BM chimera approaches confirmed that the effects of deleting TGF $\beta R 1$ were intrinsic to $\mathrm{CD} 11 \mathrm{c}^{+} \mathrm{m} \phi$, the infiltrating monocytes, which are $\mathrm{CD} 11 \mathrm{c}^{-}$and express low levels of Tgfbrl, were derived from both $T g f b r \mathrm{f}^{\mathrm{fl} / \mathrm{fl}}$ and wild-type sources in the mixed chimeras. Therefore, this phenomenon appears to be a bystander consequence of the lack of TGF $\beta$ dependent control of $m \phi$ function. The exact basis of this effect remains to be determined, but it was associated with enhanced expression of mRNA for the monocyte chemoattractant CCL8 by colonic $m \phi$. In parallel, the cell intrinsic deficiency of TGF $\beta R 1$ in $m \phi$ was accompanied by an expanded number of $\mathrm{CD} 169^{+} \mathrm{m} \phi$, a population that has recently been shown to be involved in monocyte recruitment via production of CCL8. ${ }^{25}$ Thus, TGF $\beta R 1$ signaling may control how colonic $\mathrm{m} \phi$ regulate the rate of monocyte recruitment to the mucosa.
We initially hypothesized that the dysregulated monocyte$\mathrm{m} \phi$ waterfall occurred because $T g f b r 1^{-1-}$ colonic $\mathrm{m} \phi$ had become unusually responsive to local pro-inflammatory stimuli. However these cells actually produced less TNF $\alpha$ than littermate controls both after stimulation and under resting conditions. Although these findings contrast with previous experiments showing that exogenous TGF $\beta$ can inhibit pro-inflammatory responses by human blood monocytes, ${ }^{19,32}$ such in vitro conditions may not recapitulate the in vivo environment. In our hands, steady state and LPSstimulated $\mathrm{Cre}^{+} \mathrm{m} \phi$ also produced less IL10 than control $\mathrm{m} \phi$, although this was associated with only a rather limited disruption of the monocyte- $\mathrm{m} \phi$ continuum in vivo, consistent with recent results that signaling through the IL10R in $\mathrm{m} \phi$ is much more important for preventing inflammation than their ability to produce IL10 itself. ${ }^{28,29,31}$ Our microarray comparison of Tgfbr1 ${ }^{-1-}$ and Il1Ora ${ }^{-1-}$ colonic m $\phi$ provided further evidence that these cytokines regulate $\mathrm{m} \phi$ activity by different mechanisms, as there was little or no overlap in the genes whose expression was altered in these animals. As above, it should be noted that these experiments compared gene expression changes in IL10R-deficient $\mathrm{m} \phi$ from immunocompetent mice with those in Tgfbr1-deficient $\mathrm{m} \phi$ from mice on the Rag1 $1^{-1-}$ background. Therefore, we cannot exclude the possibility that the transcriptional differences might vary if the strains were maintained on similar backgrounds. Together our results indicate that TGF $\beta$ and IL10 have complementary roles in imprinting intestinal $\mathrm{m} \phi$, with TGF $\beta$ shaping their tissue repair and scavenging functions, whereas IL10 controls the production of pro-inflammatory mediators. That IL10 and TGF $\beta$ may have distinct effects on controlling intestinal inflammation in vivo are consistent with experiments in which TGF $\beta$ inhibited $\gamma$ IFN production in intestinal explants by limiting IL12 production, whereas IL10 did this by reducing caspase-1mediated generation of IL18. ${ }^{45}$

Our discovery of TGF $\beta$ as being critical for the functional specification of intestinal $\mathrm{m} \phi$ adds to the growing list of factors that drive the differentiation of $\mathrm{m} \phi$ in a tissue-specific manner. ${ }^{7,22,23,46-48}$ However, TGF $\beta$ alone clearly cannot explain all aspects of intestinal $\mathrm{m} \phi$ differentiation, consistent with the evidence from other tissues that multiple factors, including specific cytokines and transcription factors act synergistically to imprint the full phenotypic and functional signature of resident $\mathrm{m} \phi .^{49}$ Interestingly, the transcription factor RUNX3 was highlighted in a recent study of the transcriptome and epigenome of intestinal $m \phi .{ }^{15}$ RUNX3 mediates TGF $\beta$ responsiveness in several cell types and TGF $\beta R$ signaling cooperates with PU.1 in RUNX3 driven development of Langerhans cells. ${ }^{50-52}$ Other mediators that can influence intestinal $\mathrm{m} \phi$ development include CSF $1^{53}$ and $\mathrm{Notch}^{54}$ and interestingly, we found that TGF $\beta \mathrm{R}$ signaling regulated the expression of genes involved in the Notch signaling pathway, including Hes1 and Dtx4. The retinoic acid and aryl hydrocarbon receptor signaling pathways also both have abundant ligands in the intestine and RA is known to regulate intestinal DC development, ${ }^{55}$ whereas the aryl hydrocarbon receptor- 
inducible regulatory gene Ahrr is part of the colonic $\mathrm{m} \phi$ signature we identified. Furthermore, microbes and their products are known to influence the behavior ${ }^{56}$ and turnover of colonic $\mathrm{m} \phi .{ }^{9}$ Dissecting the interaction of different pathways in regulating intestinal $\mathrm{m} \phi$ development and the factors involved is an important goal for the future.

\section{METHODS}

Mice. WT C57Bl/6 (CD45.2 $\left.{ }^{+}\right), \mathrm{C} 57 \mathrm{Bl} / 6 . \mathrm{SJL}\left(\mathrm{CD} 45.1^{+}\right), \mathrm{CD} 45.1^{+} /$ $\mathrm{CD} 45.2^{+}, \mathrm{C} \times 3 \mathrm{crl}^{\mathrm{GFP} /+}, 57 \mathrm{CD} 11 \mathrm{c}-\mathrm{Cre} . \mathrm{Tgfbr} 1^{\mathrm{fl} / \mathrm{fl}}$ mice have been described previously ${ }^{58}$ and were generated by crossing Itgax-Cre mice ${ }^{59}$ with mice carrying LoxP sites at exon 3 of the Tgfbr 1 gene ${ }^{60}$ and maintained on a Rag1 ${ }^{-1}$ background. Ccr2 $2^{-1-61}$ were backcrossed onto the C57Bl/6.SJL (CD45.1 ${ }^{+}$) background. CD11c-Cre.Rosa26LSL-eYFP mice were generated by crossing Itgax-Cre mice with homozygous Rosa26-LSL-YFP mice (a gift from Dr Megan Macleod, University of Glasgow). All mice had been backcrossed for at least nine generations onto the B6 background and were used at 6-12 weeks of age. Age-matched mice were used in all experiments for all groups. Male and female mice were used throughout the study and all mice were bred and maintained at the Central Research Facility at the University of Glasgow under specified pathogen-free conditions under licence by the UK Home Office and approved by the University of Glasgow Local Ethical Review Panel.

Cell isolation. Intestinal lamina propria leukocytes were isolated as described previously ${ }^{62}$ (Cerovic, 2013). In brief, colons and small intestines were removed, Peyer's patches were excised from small intestines, the tissues were cleared of luminal contents and opened longitudinally. Tissue was incubated at $37^{\circ} \mathrm{C}$ shaking twice for $15 \mathrm{~min}$ in HBSS ( $2 \mathrm{~mm}$ ethylenediaminetetraacetic acid) to remove the epithelial layer and then digested in complete RPMI 1640 (RPMI supplemented with $10 \%$ fetal calf serum, $2 \mathrm{~mm} \mathrm{~L}$-glutamine, $100 \mathrm{U} \mathrm{ml}^{-1}$ penicillin, $100 \mu \mathrm{g} \mathrm{ml}^{-1}$ streptomycin, and $50 \mu \mathrm{M} 2$-mercaptoethanol; all Gibco, Life Technologies, Paisley, UK) containing $0.425 \mathrm{mg} \mathrm{ml}^{-1}$ collagenase V (Sigma-Aldrich, Poole, UK), $0.625 \mathrm{mg} \mathrm{ml}^{-1}$ collagenase $\mathrm{D}$ (Roche, Diagnostics, Burgess Hill, UK), $1 \mathrm{mg} \mathrm{m}^{-1}$ dispase (Gibco), $30 \mu \mathrm{g} \mathrm{ml}^{-1}$ DNase (Roche) for the colon, or $1 \mathrm{mg} \mathrm{ml}^{-1}$ Collagenase VIII (Sigma-Aldrich) for the small intestine for 40 min shaking at $37^{\circ} \mathrm{C}$. Dermal leukocytes were isolated as described previously. ${ }^{63}$

Flow cytometry and cell sorting. Following incubation with purified anti-CD16/CD32 for 10 mins at $4{ }^{\circ} \mathrm{C}, 1-10 \times 10^{6}$ cells were stained at $4{ }^{\circ} \mathrm{C}$ in the dark using the antibodies listed in Supplementary Table 5 and analyzed using an LSR II or FACSAriaI/III cytometer (BD Biosciences, San Jose, CA) and FlowJo software (Tree Star, Ashland, OR). 7AAD or Fixable Viability Dye eFluor510 or eFluor780 was used to eliminate dead cells from analysis. For microarray analysis of colonic P1-P4 subsets, cells were sorted according to. ${ }^{8}$ For microarray analysis of colonic $\mathrm{m} \phi$ from CD11c-Cre-Tgfbr $1^{\mathrm{fl} / \mathrm{l}}$ mice, cells were sorted using the gating strategy detailed in Supplementary Figure $\mathbf{3 b}$.

Cell stimulation and cytokine measurement in vitro. For intracellular cytokine detection, whole colonic lamina propria isolates were incubated in complete RPMI with monensin (Biolegend, UK, London, UK; $1: 1,000$ ) and brefeldin A (Biolegend, UK; 1:1,000) with or without LPS $\left(1 \mu \mathrm{g} \mathrm{ml}^{-1}\right)$ for $4.5 \mathrm{~h}$ in sterile capped polystyrene tubes at $37^{\circ} \mathrm{C}$ in $5 \% \mathrm{CO}_{2}$. Intracellular staining for IL10 and TNF $\alpha$ was performed following surface staining and fixation and permeabilisation using the BD Cytofix/Cytoperm kit.

Generation of BM chimeras. Six to eight week old CD45.1 ${ }^{+} \mathrm{CD} 45.2^{+}$ WT mice were lethally irradiated with two doses of $5 \mathrm{~Gy}$ with an interval of $1 \mathrm{hr}$ and reconstituted immediately by intravenous infusion of $5 \times 10^{6} \mathrm{BM}$ cells from CD45.1 $1^{+}$WT mice together with BM from CD 45.2 $2^{+}$CD11c-Cre.Tgfbr1 ${ }^{\mathrm{f} / \mathrm{fl}} \mathrm{Rag1}^{-1-}\left(\mathrm{Cre}^{+}\right)$or $\mathrm{Tg} f b r 1^{\mathrm{fl} / \mathrm{fl}}$ mice $\left(\mathrm{Cre}^{-}\right)$mice at a ratio of $1: 1$. In some experiments, recipients were reconstituted with $\mathrm{BM}$ from $\mathrm{Ccr} 2^{-1-}\left(\mathrm{CD} 45.1^{+}\right)$mice and CD45.2 $2^{+}$ CD11c-Cre.Tgfbr $1^{\mathrm{fl} / \mathrm{fl}}$ mice Rag1 ${ }^{-/-}\left(\mathrm{Cre}^{+}\right)$or $\mathrm{Tg} f b r 1^{\mathrm{l} / \mathrm{fl}}$ mice $\left(\mathrm{Cre}^{-}\right)$ mice at a ratio of 1:1. Mice were left for at least 8 weeks before analysis.

Quantitation of gene expression by real-time reverse transcription PCR. Total RNA was extracted from FACS-purified colonic subsets of individual adult mice or BM chimeric mice using the RNeasy Micro kit (Qiagen, Crawley, UK). RNA was reverse transcribed to complementary DNA using the Superscript II First strand synthesis system (Invitrogen, Paisley, UK) and gene expression was assayed by quantitative reverse transcription PCR using Brilliant III Ultra Fast SYBR qPCR master mix (Agilent Technologies, Workingham, UK) on the 7500 HT Fast system (Applied Biosystems, Paisley, UK). Primers using the primers (Integrated DNA Technologies, Glasgow, UK) are detailed in Supplementary Table 6. Complementary DNA samples were assayed in triplicate and gene expression levels were normalized to Cyclophilin A. The mean relative gene expression was calculated using the $2^{-\mathrm{dC}(\mathrm{t})}$ method.

Histological analysis. Sections of colon were fixed in $2 \%$ formaldehyde, embedded in paraffin, and stained with Hematoxylin \& Eosin (Sigma) for assessment of intestinal architecture.

Microarray analysis. Microarray analysis was performed in triplicate. Cell populations from colonic cell isolates were sort-purified and RNA was isolated using the RNeasy Micro Kit (Qiagen).

The microarray study of $\mathrm{m} \phi$ populations from CD11c-Cre.Tgfbr $1^{\mathrm{f} / \mathrm{fl}}$ mice Rag1 ${ }^{-1-}$ mice was performed in the Research Core Unit Transcriptomics of the Hannover Medical School using a refined version of the Whole Mouse Genome Oligo Microarray $444 \mathrm{~K}$ v2 (Design ID 026655, Agilent Technologies, Santa Clara, CA) (026655AsQuadruplicatesOn180k' Design ID 048306) and designed via Agilent's eArray portal using a 4,180 k design format for mRNA expression as template. All non-control probes of design ID 026655 were printed four times onto a single $180 \mathrm{k}$ Microarray. Control probes required for proper Feature Extraction software algorithms were determined and placed automatically by eArray using recommended default settings. Total RNA (4-8 ng) was used to prepare aminoallylUTP-modified (aaUTP) cRNA (Amino Allyl MessageAmp II Kit; \#AM1753; Life Technologies) as directed by the company (applying one round of amplification). The labeling of aaUTP-cRNA was performed by use of Alexa Fluor 555 Reactive Dye (\#A32756; LifeTechnologies, Darmstadt, Germany). Before the reverse transcription reaction, $1 \mathrm{ml}$ of a 1:50,000 dilution of Agilent's "One-Colour spike-in Kit stock solution" (\#5,188-5,282, Agilent Technologies) was added to each total RNA sample. cRNA fragmentation, hybridization, and washing steps were carried out as recommended in the "One-Colour Microarray-Based Gene Expression Analysis Protocol V5.7", except that $45 \mathrm{ng}$ of each fluorescently labeled cRNA population were used for hybridization. Slides were scanned on the Agilent Micro Array Scanner G2565CA (pixel resolution $3 \mathrm{~mm}$, bit depth 20). Data extraction was performed with the "Feature Extraction Software V10.7.3.1" using the extraction protocol file "GE1_107_Sep09.xml”. Extracted raw data were imported into Omics software 3.2 (Qlucore, Lund, Sweden) under default import settings for Agilent One-Color mRNA Microarrays. Accordingly, data processing steps were: (1) removal of control measurements, (2) log base 2 transformation, (3) normalization of non-control values by shifting to 75 Percentile, (4) averaging of values from on-chip replicates, and (5) baseline transformation to the median.

The microarray study of monocyte and $\mathrm{m} \phi$ populations from $\mathrm{C} \times 3 \mathrm{cr} 1^{\mathrm{GFP} /+}$ mice was performed by use of GeneChip Mouse Gene 1.0 ST arrays (Affymetrix, Santa Clara, CA). Quantity, quality, and absence of genomic DNA contamination were assessed with a Bioanalyser (Agilent). Biotinylated double-strand complementary DNA targets were prepared, starting from 4.9 ng to 20 ng of total RNA using the NuGEN Ovation Pico WTA System V2 Kit and the NuGEN Encore Biotin Module Kit according to NuGEN recommendations. Following fragmentation and end-labeling, $2.07 \mu \mathrm{g}$ of complementary 
DNAs were hybridized for $16 \mathrm{~h}$ at $45^{\circ} \mathrm{C}$ on GeneChip Mouse Gene 1.0 ST arrays (Affymetrix) interrogating 28,853 genes represented by $\sim 27$ probes spread across the full length of the gene. The chips were washed and stained in the GeneChip Fluidics Station 450 (Affymetrix) and scanned with the GeneChip Scanner 3000 7G (Affymetrix) at a resolution of $0.7 \mu \mathrm{m}$. Raw data (CEL Intensity files) were extracted from the scanned images using the Affymetrix GeneChip Command Console (AGCC) version 3.2. The CEL Intensity files were further processed using the Omics software 3.2 (Qlucore). They were imported using the default import process for GeneChip Mouse Gene 1.0 ST arrays (Affymetrix) using RMA-Sketch Normalization.

Omics software 3.2 (Qlucore) was used to generate heat maps and to classify cell subsets according to the proximity of their gene expression pattern as assessed by hierarchical clustering with average linkage. Lists of genes showing differential expression between two different conditions were generated and the expression levels in the heatmaps are represented as $\log _{2}$ transformations.

Enrichment analyses was performed using WebGestalt ${ }^{64}$ all the genes present on the GeneChip Mouse Gene 1.0 ST array were used as a reference ( $\mathrm{N}$ genes in the reference gene set $\mathrm{B}$ ). Genes within this set that changed by at least twofold with a $P$ value lower than 0.05 during the differentiation from $\mathrm{P} 1$ to $\mathrm{P} 4$ in the colon were defined as the gene set of interest ( $\mathrm{n}$ genes in the interesting gene set $\mathrm{A}$ ). $\mathrm{k}$ genes in $\mathrm{A}$ and $\mathrm{K}$ genes in $\mathrm{B}$ are given in a specific category $\mathrm{C}$. The hypergeometric test to evaluate the significance of enrichment for category $\mathrm{C}$ in gene set $\mathrm{A}$ is:

$P=\sum_{i=k}^{n} \frac{\left(\begin{array}{c}N-K \\ n-i\end{array}\right)\left(\begin{array}{c}K \\ i\end{array}\right)}{\left(\begin{array}{c}N \\ n\end{array}\right)}$. As multiple categories in a group of functional gene set categories were being compared, the $P$ value was adjusted using R function p.adjust based on Benjamini Hochberg.

The microarray data have been deposited in the Gene Expression Omnibus and will be made available upon publication. Public expression data from the ImmGen compendium (Heng and Painter, 2008) of mouse tissue $m \phi$ subsets were retrieved from the GEO data set GSE15907. The expression data from the dermal tissue were retrieved from the GEO data set GSEGSE49358.

Accession numbers. The microarray data have been deposited in the Gene Expression (GEO) database (http://www.ncbi.nlm.nih.gov/gds) under accession numbers GSE84764 (Colonic P1-P4 array data) and GSE84765 (Colonic TGFßR array data).

Statistics. Statistical analysis was performed using GraphPad Prism software. All data are presented as mean \pm s.d. and $P=0.05$ are considered as significant. Statistical tests used and levels of significance are detailed in each figure legend. Statistical analysis of microarray data was performed using Omics software 3.2 (Qlucore). Student's $t$-test was used to compare two groups, while multiple groups were compared using analysis of variance or Student's $t$-tests with appropriate corrections as detailed in the legends. A $P$ value of 0.05 was considered significant.

SUPPLEMENTARY MATERIAL is linked to the online version of the paper at http://www.nature.com/mi

\section{ACKNOWLEDGMENTS}

We thank Dr Ruairi Lynch and Cathy Hawley for critical reading of the manuscript, Ms Diane Vaughan at the Glasgow Flow Cytometry Facility for help with sorting, Dr Moritz Muschaweck for his assistance with histological analysis. Microarray data of colonic $\mathrm{m} \phi$ from $\mathrm{CD} 11 \mathrm{c}-\mathrm{Cre}$.Tgfbr $1^{\mathrm{fl} / \mathrm{fl}}$ mice were generated by the Research Core Unit Transcriptomics of the Hannover Medical School. This work was supported by the Wellcome Trust UK, the Medical Research Council UK, Tenovus Scotland, the German Research Foundation grant DFG PA921/2-1 (OP), European Research Council FP7/2007-2013 grants no. 322465 (BM) and 281225 (MD) ANR grant SkinDC (SH), the Hannover Biomedical Research School, and the Center for Infection Biology (ZIB).

\section{AUTHOR CONTRIBUTIONS}

A.S., C.C.B., Jo.Ma., and Je.Mo. performed experiments and analyzed data. A.S., E.P., B.D., M.D., and S.H. carried out and interpreted the transcriptional analyses. S.J.J. provided expert advice. A.M.M., O.P., B.M., S.W.M., and S.H. supervised different parts of the project. C.C.B. and A.M.M. conceived and directed the study. AS, C.C.B., O.P., and A.M.M. wrote the manuscript and all authors edited the manuscript.

\section{DISCLOSURE}

The authors declare no conflict of interest.

Official journal of the Society for Mucosal Immunology

\section{REFERENCES}

1. Perdiguero, E. G. \& Geissmann, F. The development and maintenance of resident macrophages. Nat. Immunol. 17, 2-8 (2015).

2. Okabe, Y. \& Medzhitov, R. Tissue biology perspective on macrophages. Nat. Immunol. 17, 9-17 (2016).

3. Ginhoux, F. \& Guilliams, M. Tissue-resident macrophage ontogeny and homeostasis. Immunity 44, 439-449 (2016).

4. Gomez Perdiguero, E. et al. Tissue-resident macrophages originate from yolk-sac-derived erythro-myeloid progenitors. Nature 518, 547-551 (2015).

5. Hoeffel, G. et al. C-Myb $(+)$ erythro-myeloid progenitor-derived fetal monocytes give rise to adult tissue-resident macrophages. Immunity 42, 665-678 (2015)

6. Sheng, J., Ruedl, C. \& Karjalainen, K. Most tissue-resident macrophages except microglia are derived from fetal hematopoietic stem cells. Immunity 43, 382-393 (2015).

7. Guilliams, M. et al. Alveolar macrophages develop from fetal monocytes that differentiate into long-lived cells in the first week of life via GM-CSF. J. Exp. Med. 210, 1977-1992 (2013).

8. Bain, C. C. et al. Resident and pro-inflammatory macrophages in the colon represent alternative context-dependent fates of the same Ly6Chi monocyte precursors. Mucosal Immunol. 6, 498-510 (2013).

9. Bain, C. C. et al. Constant replenishment from circulating monocytes maintains the macrophage pool in the intestine of adult mice. Nat. Immunol. 15, 929-937 (2014).

10. Tamoutounour, S. et al. Origins and functional specialization of macrophages and of conventional and monocyte-derived dendritic cells in mouse skin. Immunity 39, 925-938 (2013).

11. Epelman, S. et al. Embryonic and adult-derived resident cardiac macrophages are maintained through distinct mechanisms at steady state and during inflammation. Immunity 40, 91-104 (2014).

12. Molawi, K. et al. Progressive replacement of embryo-derived cardiac macrophages with age. J. Exp. Med. 211, 2151-2158 (2014).

13. Heidt, T. et al. Differential contribution of monocytes to heart macrophages in steady-state and after myocardial infarction. Circ. Res. 115, 284-295 (2014).

14. Bain, C. C. et al. Long-lived self-renewing bone marrow-derived macrophages displace embryo-derived cells to inhabit adult serous cavities. Nat. Commun. 7, ncomms11852 (2016).

15. Lavin, Y. et al. Tissue-resident macrophage enhancer landscapes are shaped by the local microenvironment. Cell 159, 1312-1326 (2014).

16. van de Laar, L. et al. Yolk sac macrophages, fetal liver, and adult monocytes can colonize an empty niche and develop into functional tissue-resident macrophages. Immunity 44, 755-768 (2016).

17. Lee, S. H., Starkey, P. M. \& Gordon, S. Quantitative analysis of total macrophage content in adult mouse tissues. Immunochemical studies with monoclonal antibody F4/80. J. Exp. Med. 161, 475-489 (1985).

18. Tamoutounour, S. et al. CD64 distinguishes macrophages from dendritic cells in the gut and reveals the Th1-inducing role of mesenteric lymph node macrophages during colitis. Eur. J. Immunol. 42, 3150-3166 (2012).

19. Smythies, L. E. et al. Inflammation anergy in human intestinal macrophages is due to Smad-induced IkappaBalpha expression and NF-kappaB inactivation. J. Biol. Chem. 285, 19593-19604 (2010).

20. Platt, A. M., Bain, C. C., Bordon, Y., Sester, D. P. \& Mowat, A. M. An independent subset of TLR expressing CCR2-dependent macrophages promotes colonic inflammation. J. Immunol. 184, 6843-6854 (2010). 
21. Zigmond, E. et al. Ly6C hi monocytes in the inflamed colon give rise to proinflammatory effector cells and migratory antigen-presenting cells. Immunity 37, 1076-1090 (2012).

22. Okabe, Y. \& Medzhitov, R. Tissue-specific signals control reversible program of localization and functional polarization of macrophages. Cell 157, 832-844 (2014).

23. Schneider, C. et al. Induction of the nuclear receptor PPAR- $\gamma$ by the cytokine GM-CSF is critical for the differentiation of fetal monocytes into alveolar macrophages. Nat. Immunol. 15, 1026-1037 (2014).

24. Gautier, E. L. et al. Gene-expression profiles and transcriptional regulatory pathways that underlie the identity and diversity of mouse tissue macrophages. Nat. Immunol. 13, 1118-1128 (2012).

25. Asano, K. et al. Intestinal CD169(+) macrophages initiate mucosal inflammation by secreting CCL8 that recruits inflammatory monocytes. Nat. Commun. 6, 7802 (2015).

26. Butovsky, O. et al. Identification of a unique TGF- $\beta$-dependent molecular and functional signature in microglia. Nat. Neurosci. 17, 131-143 (2014).

27. Rivollier, A., He, J., Kole, A., Valatas, V. \& Kelsall, B. L. Inflammation switches the differentiation program of Ly6Chi monocytes from antiinflammatory macrophages to inflammatory dendritic cells in the colon. J. Exp. Med. 209, 139-155 (2012).

28. Zigmond, E. et al. Macrophage-restricted interleukin-10 receptor deficiency, but not IL-10 deficiency, causes severe spontaneous colitis. Immunity 40, 720-733 (2014).

29. Shouval, D. S. et al. Interleukin-10 receptor signaling in innate immune cells regulates mucosal immune tolerance and anti-inflammatory macrophage function. Immunity 40, 706-719 (2014).

30. Hoshi, N. et al. MyD88 signalling in colonic mononuclear phagocytes drives colitis in IL-10-deficient mice. Nat. Commun. 3, 1120 (2012).

31. Girard-Madoux, M. J. H. et al. IL-10 control of CD11C + myeloid cells is essential to maintain immune homeostasis in the small and large intestine. Oncotarget 7, 32015-32030 (2016).

32. Maheshwari, A. et al. TGF-beta2 suppresses macrophage cytokine production and mucosal inflammatory responses in the developing intestine. Gastroenterology 140, 242-253 (2011).

33. Jakubzick, C. et al. Minimal differentiation of classical monocytes as they survey steady-state tissues and transport antigen to lymph nodes. Immunity 39, 599-610 (2013).

34. Ruggiero, L., Connor, M. P., Chen, J., Langen, R. \& Finnemann, S. C. Diurnal, localized exposure of phosphatidylserine by rod outer segment tips in wild-type but not Itgb5 - / - or Mfge8 - / - mouse retina. Proc. Natl. Acad. Sci. USA 109, 8145-8148 (2012).

35. Lacy-Hulbert, A. et al. Ulcerative colitis and autoimmunity induced by loss of myeloid alphav integrins. Proc. Natt. Acad. Sci. USA 104, 15823-15828 (2007).

36. Bauer, T. et al. Identification of Axl as a downstream effector of TGF- $\beta 1$ during Langerhans cell differentiation and epidermal homeostasis. J. Exp. Med. 209, 2033-2047 (2012).

37. Morton, P. E. et al. TNF $\alpha$ promotes CAR-dependent migration of leukocytes across epithelial monolayers. Sci. Rep. 6, 26321 (2016).

38. Niess, J. H. et al. CX3CR1-mediated dendritic cell access to the intestinal lumen and bacterial clearance. Science 307, 254-258 (2005).

39. Chieppa, M., Rescigno, M., Huang, A. Y. \& Germain, R. N. Dynamic imaging of dendritic cell extension into the small bowel lumen in response to epithelial cell TLR engagement. J. Exp. Med. 203, 2841-2852 (2006).

40. Garlanda, C., Riva, F., Bonavita, E. \& Mantovani, A. Negative regulatory receptors of the IL-1 family. Semin. Immunol. 25, 408-415 (2013).

41. Huber, S. et al. IL-22BP is regulated by the inflammasome and modulates tumorigenesis in the intestine. Nature 491, 259-263 (2012).

42. Dinarello, C. A., Novick, D., Kim, S. \& Kaplanski, G. Interleukin-18 and IL-18 binding protein. Front. Immunol. 4, 289 (2013).

43. Yang, J. et al. The novel costimulatory programmed death ligand 1/B7.1 pathway is functional in inhibiting alloimmune responses in vivo. J. Immunol. 187, 1113-1119 (2011).

44. Varol, C. et al. Intestinal lamina propria dendritic cell subsets have different origin and functions. Immunity 31, 502-512 (2009).

45. Jarry, A., Bossard, C., Sarrabayrouse, G., Mosnier, J.-F. \& Laboisse, C. L. Loss of interleukin-10 or transforming growth factor $\beta$ signaling in the human colon initiates a T-helper 1 response via distinct pathways. Gastroenterology 141, 1887-96.e1-2 (2011).

46. Rosas, M. et al. The transcription factor Gata6 links tissue macrophage phenotype and proliferative renewal. Science 344, 645-648 (2014).

47. Gautier, E. L. et al. Gata6 regulates aspartoacylase expression in resident peritoneal macrophages and controls their survival. J. Exp. Med 211, 1525-1531 (2014).

48. A-Gonzalez, N. et al. The nuclear receptor $L X R \alpha$ controls the functional specialization of splenic macrophages. Nat. Immunol. 14, 831-839 (2013).

49. Lavin, Y., Mortha, A., Rahman, A. \& Merad, M. Regulation of macrophage development and function in peripheral tissues. Nat. Rev. 15, 731-744 (2015).

50. Fainaru, O. et al. Runx3 regulates mouse TGF-beta-mediated dendritic cell function and its absence results in airway inflammation. EMBO J. 23, 969-979 (2004).

51. Brenner, O. et al. Loss of Runx 3 function in leukocytes is associated with spontaneously developed colitis and gastric mucosal hyperplasia. Proc. Natl. Acad. Sci. USA 101, 16016-16021 (2004).

52. Chopin, M. et al. Langerhans cells are generated by two distinct PU.1dependent transcriptional networks. J. Exp. Med. 210, 2967-2980 (2013).

53. Schlitzer, A. et al. IRF4 transcription factor-dependent CD11b + dendritic cells in human and mouse control mucosal IL-17 cytokine responses. Immunity 38, 970-983 (2013).

54. Ishifune, C. et al. Differentiation of CD11C + CX3CR1 + cells in the small intestine requires Notch signaling. Proc. Natl. Acad. Sci. USA 111, 59865991 (2014).

55. Klebanoff, C. A. et al. Retinoic acid controls the homeostasis of pre-cDCderived splenic and intestinal dendritic cells. J. Exp. Med. 210, 1961-1976 (2013).

56. Ueda, Y. et al. Commensal microbiota induce LPS hyporesponsiveness in colonic macrophages via the production of IL-10. Int. Immunol. 22, 953-962 (2010).

57. Jung, S. et al. Analysis of fractalkine receptor $\mathrm{CX}(3) \mathrm{CR} 1$ function by targeted deletion and green fluorescent protein reporter gene insertion. Mol. Cell Biol. 20, 4106-4114 (2000).

58. Kel, J. M., Girard-Madoux, M. J. H., Reizis, B. \& Clausen, B. E. TGF-beta is required to maintain the pool of immature Langerhans cells in the epidermis. J. Immunol. 185, 3248-3255 (2010).

59. Caton, M. L., Smith-Raska, M. R. \& Reizis, B. Notch-RBP-J signaling controls the homeostasis of CD8- dendritic cells in the spleen. J. Exp. Med. 204, 1653-1664 (2007).

60. Larsson, J. et al. Abnormal angiogenesis but intact hematopoietic potential in TGF-beta type I receptor-deficient mice. EMBO J. 20, 1663-1673 (2001).

61. Boring, L. et al. Impaired monocyte migration and reduced type 1 (Th1) cytokine responses in C-C chemokine receptor 2 knockout mice. J. Clin. Invest. 100, 2552-2561 (1997).

62. Bain, C. C. \& Mowat, A. M. CD200 receptor and macrophage function in the intestine. Immunobiology 217, 643-651 (2011).

63. Henri, S. et al. CD207 + CD103 + dermal dendritic cells cross-present keratinocyte-derived antigens irrespective of the presence of Langerhans cells. J. Exp. Med. 207, 189-206 (2010).

64. Wang, J., Duncan, D., Shi, Z. \& Zhang, B. WEB-based GEne SeT AnaLysis Toolkit (WebGestalt): update 2013. Nucleic Acids Res. 41, W77-W83 (2013).

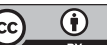

This work is licensed under a Creative Commons Attribution 4.0 International License. The images or other third partymaterialin thisarticleareincluded in thearticle's Creative Commons license, unless indicated otherwise in the credit line; if the material is not included under the Creative Commons license, users will need to obtain permission from the license holder to reproduce the material. To view a copy of this license, visit http://creativecommons.org/licenses/by/4.0/

(C) The Author(s) 2017 